\title{
Bioactive Indanes: Comparative In Vitro Metabolism Study of PH46A, a New Potential Anti-inflammatory Agent and biosynthesis of its primary metabolite $\mathrm{PH} 132$
}

\author{
Tao Zhang \\ Technological University Dublin, tao.zhang@tudublin.ie \\ Gaia Scalabrino \\ Trino Therapeutics Ltd \\ Neil Frankish \\ Trinity College Dublin
}

See next page for additional authors

Follow this and additional works at: https://arrow.tudublin.ie/schfsehart

Part of the Life Sciences Commons

\section{Recommended Citation}

Zhang, T., Scalabrino, G., Frankish, N. and Sheridan, H. (2018). Bioactive indanes: comparative in vitro metabolism study of PH46A, a new potential anti-inflammatory agent and biosynthesis of its primary metabolite PH132. Journal of Drug Metabolism \& Toxicology, 9, pp.1-14. doi:10.1016/

J.JPBA.2019.113011

This Article is brought to you for free and open access by the School of Food Science and Environmental Health at ARROW@TU Dublin. It has been accepted for inclusion in Articles by an authorized administrator of ARROW@TU

Dublin. For more information, please contact

arrow.admin@tudublin.ie, aisling.coyne@tudublin.ie, gerard.connolly@tudublin.ie.

Funder: The Wellcome Trust UK

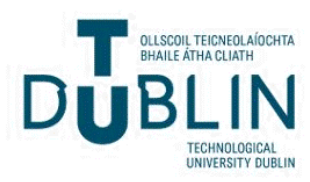




\section{Authors}

Tao Zhang, Gaia Scalabrino, Neil Frankish, and Helen Sheridan 


\title{
Bioactive Indanes: Comparative in vitro Metabolism Study of PH46A, a New Potential Anti-inflammatory Agent and Biosynthesis of its Primary Metabolite PH132
}

\author{
Tao Zhang1, Gaia Scalabrino' ${ }^{1}$, Neil Frankish ${ }^{1,2}$ and Helen Sheridan ${ }^{1,2^{\star}}$ \\ ${ }^{1}$ Trino Therapeutics Ltd., The Tower, Trinity Technology and Enterprise Campus, Ireland \\ ${ }^{2}$ Novel Drug Discovery Group, School of Pharmacy and Pharmaceutical Sciences \& Trinity Biomedical Sciences Institute, Trinity College, Ireland
}

\begin{abstract}
$\mathrm{PH} 46 \mathrm{~A}$ is the lead of a new class of bioactive indanes with potential for the treatment of inflammatory bowe disease. A qualitative in vitro metabolism profile of $\mathrm{PH} 46 \mathrm{~A}$ was investigated in preclinical studies, and the rate of its metabolism in cryopreserved hepatocytes prepared from male Sprague Dawley rat, Beagle dog, Cynomolgus monkey and pooled mixed gender human was compared by LC-MS. The clearance order of PH46A was determined to be rat>dog>monkey>human. The species tested which exhibited the closest clearance values to the human was monkey. Following incubation of PH46A with cryopreserved hepatocytes, 5 metabolites were identified, including M1 (keto-PH46), M2 (PH46-OH, PH132), M3 (PH46-diOH), M4 (keto-glucuronide-PH46) and M5 (glucuronide conjugate-PH46). It was found that the human metabolites M2 and M5 were also present in rat, dog and monkey, while M1 was present in all species except monkey. M2 was detected in dog and monkey by LC1 conditions, but only in dog by LC2. Therefore, the metabolism in rat was most similar to human, in terms of the metabolites observed, but all putative human metabolites were present in rat and dog. We further explored the characterization of key metabolite $\mathrm{M} 2(\mathrm{PH} 46-\mathrm{OH})$. Identical $\mathrm{PH} 46-\mathrm{OH}$ was obtained via a bio-catalytic oxidation method from $\mathrm{PH} 46$ using rat liver microsomes (RLM) and the human liver P450s (Cyp2D6, Cyp 2C19 and Cyp 4A11) following screening of selectAZyme panels of microbial P450s, recombinant human liver P450s and different microsomes. RLM was used in scale up production and $\mathrm{PH} 132$ was isolated and characterized as 4-(((1'S, 2'S)-1',6-dihydroxy-1',3'-dihydro-

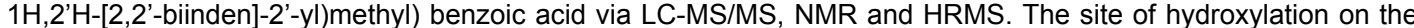
biindane scaffold was unexpected. The outcomes of these studies have provided valuable information for future pharmacokinetic and in vivo toxicological investigations.
\end{abstract}

Keywords: Bioactive indane; PH46A; PH46; Metabolism; PH132; LC-MS; Biosynthesis

\section{Introduction}

A wide range of bioactive indane based scaffolds are employed clinically as treatment of many disease states, including inflammatory [1-3], cancer [4,5] and neurological conditions [6] and also in the treatment of HIV [7]. Several classes of diastereoisomeric and enantiomeric molecules containing the indane moiety have been developed and characterized by our group [8-10]. Smooth muscle relaxation and mediator release inhibition properties have been demonstrated for many of these novel compounds [11-13]. In continuation of our work, we more recently designed and synthesized a series of dimeric indane compounds, with two contiguous stereogenic centres, one of which is a quaternary centre. Some of these compounds possess potent anti-inflammatory activity, in particular, a lead chiral molecule PH46A with $S, S$ configurations [14-18], has been identified by our group and was subject to a range of preclinical studies prior to entering a Phase I clinical trial [19].

$\operatorname{ADME}$ (Absorption, distribution, metabolism, and excretion) is one of the major elements involved in the drug discovery and development process. In the last two decades, comparative in vitro metabolism studies of different species has been widely employed as a more costeffective approach to understand the animal toxicological results and the relevance to humans, and to characterize new drug candidates in the early drug discovery phase [20]. In the present study, we conducted an in vitro metabolism study of PH46A in cryopreserved hepatocytes of male Sprague Dawley rat, Beagle dog, Cynomolgus monkey and pooled mixed gender human in order to: (a) to identify the potential metabolites of PH46A and pathways of metabolism in each species; (b) to identify the presence/absence of unique human metabolites; (c) to compare the rates of metabolism of PH46A by determination of loss of PH46A across the species using liquid chromatography-tandem mass spectrometry (LC-MS/MS).

Based on the metabolism data obtained, the major metabolite across all species, M2 hydroxylated $\mathrm{PH} 46$ ( $\mathrm{PH} 46-\mathrm{OH}$ or $\mathrm{PH} 132$ ) was further studied in order to support the next phase of pharmacokinetic investigation. The work was started with an extensive screening of 18 recombinant human liver P450 monooxygenases, 40 microbial P450 monooxygenases and 4 microsomes against PH46, followed by LC-MS/ MS analysis with the aim of identifying the metabolite PH132 observed in the metabolism study. The cytochrome P450 monooxygenases (P450s or Cyps) are a large family of heme protein containing enzymes found in animals, plants and microorganisms, which are involved in drug metabolism introducing a single oxygen atom derived from molecular oxygen into an organic molecule $[21,22]$. They catalyse a variety of reactions, such as hydroxylation of aliphatic and aromatic carbons, oxidation of organic nitrogen and sulphur, epoxidation and Baeyer-Villiger oxidation. Liver microsomes (LM) contain a cocktail of

*Corresponding author: Dr. Helen Sheridan, Novel Drug Discovery Group, School of Pharmacy and Pharmaceutical Sciences, Trinity College, Dublin 2, Ireland; Tel: +353-1-8962828; Fax: +353-1-89628210; E-mail: hsheridn@tcd.ie

Received May 29, 2018; Accepted June 25, 2018; Published June 30, 2018

Citation: Zhang T, Scalabrino G, Frankish N, Sheridan H (2018) Bioactive Indanes: Comparative in vitro Metabolism Study of PH46A, a New Potential Anti-inflammatory Agent and Biosynthesis of its Primary Metabolite PH132. J Drug Metab Toxicol 9: 239. doi:10.4172/2157-7609.1000239

Copyright: (c) 2018 Zhang T, et al. This is an open-access article distributed under the terms of the Creative Commons Attribution License, which permits unrestricted use, distribution, and reproduction in any medium, provided the original author and source are credited. 
different cytochromes P450, flavin-monooxygenases, carboxylesterases, epoxide hydrolases, UDP-glucuronosyltransferases and other drugmetabolizing enzymes and therefore have a high success rate for any desired oxidation reaction [23]. In this paper, we also report the scaleup production via the chosen biotransformation system, isolation and characterization of this key metabolite PH132. The potential chirality change of PH46 $(S, S)$ with formation of the diastereomer to PH46, $(R, S)$-PH46, was also monitored.

Since PH46A salt dissociates in solution, the measurements of PH46A by LC-MS analysis throughout the two studies are related to the parent PH46 (free acid form). Based on structural similarities, compound 1 was chosen as internal standard (IS) in the metabolism study (Figure 1).

\section{Materials and Methods}

\section{Chemicals}

Test item PH46A, reference compounds [PH46, diastereomer $(R, S)-\mathrm{PH} 46$ \& keto-PH46] and Compound 1 (IS) were obtained inhouse and used after identity/purity checking. Dulbecco's Modified Eagle Medium (DMEM) was purchased from Invitrogen (UK). Tetrabutylammonium phosphate monobasic was purchased from Sigma-Aldrich (UK). 0.9\% saline was obtained from Baxter (UK). All solvents (as anhydrous, HPLC or general process grades) were obtained either commercially or locally.

\section{Biological reagents}

Male Sprague Dawley rat cryopreserved hepatocytes (Lot No. RJW), male Beagle dog cryopreserved hepatocytes (Lot No. KLI and HTU), Male Cynomologus monkey cryopreserved hepatocytes (Lot No. YHC), and mixed gender human cryopreserved hepatocytes (Lot No. NQC) were obtained from Celsis, In vitro Technologies (MD, USA). All preparations were stored in liquid nitrogen prior to use. $\left[{ }^{14} \mathrm{C}\right]$-Testosterone (Batch No. 3590023), testosterone (Batch No. 070M1626V) and $\left[{ }^{14} \mathrm{C}\right]-7$-ethoxycoumarin (7-EC) (Batch No. RUS1277) were purchased from Perkin Elmer (UK), Sigma-Aldrich (UK) and Cypex (UK), respectively. All select AZymeTM enzymes were obtained from Almac (UK) as freeze dried cell free exacts.

\section{Animals and husbandry}

Six male Sprague Dawley rats, aged 10-12 weeks at dosing, were supplied by Charles River (UK) and surgically prepared with an indwelling femoral vein cannula. After a post-surgery recovery of $c a$ 7 days and prior to dose administration, a pre-study health evaluation was conducted on these animals and the results found to be satisfactory. A standard laboratory diet and mains tap water was available to the animals. Clinical signs were monitored throughout the study in order to asses any reaction to treatment.

\section{Incubation conditions for cryopreserved hepatocytes}

The primary stock solution of PH46A (4 mM) was prepared in distilled water, which was further diluted using distilled water to give the secondary stock solution $(1 \mathrm{mM})$. PH46A dosing solutions were prepared at 40 and $10 \mu \mathrm{M}$ in culture medium DMEM from the stock solutions.

A single pooled preparation from each species was used. Hepatocytes from each species (rat, dog, monkey and human) were thawed according to the suppliers' instructions. The hepatocyte viability of each preparation was determined using the trypan blue exclusion assessment by calculating the percentage of live cells present [24]. Incubations were performed, in triplicate, in 12 well plates in an incubator with temperature of $37^{\circ} \mathrm{C}$ in a humidified atmosphere of $95 \%$ air \& $5 \% \mathrm{CO}_{2}$. Test reactions contained PH46A $(5 \mu \mathrm{M}$ or 20 $\mu \mathrm{M}$ in water) and hepatocytes $\left(1 \times 10^{6}\right.$ cells $\left./ \mathrm{mL}\right)$ in a total volume 1 $\mathrm{mL}$ of (DMEM). Each metabolic reaction was terminated after 0,30 , $60,90,120$ and $240 \mathrm{~min}$ by removing an aliquot $(100 \mu \mathrm{L})$ from the appropriate well at the appropriate time point and transferring to 100 $\mu \mathrm{L}$ of cold acidified $\mathrm{MeOH}$ containing IS $(5 \mu \mathrm{M})$. After the last timepoint sampling, the remaining sample $(400 \mu \mathrm{L})$ was mixed with cold acidified $\mathrm{MeOH}(400 \mu \mathrm{L})$ containing IS. All samples were stored at $-20^{\circ} \mathrm{C}$ until being processed. Prior to LC-MS analysis, the samples were thawed and the aqueous $\mathrm{MeOH}$ supernatants were obtained following centrifugation (10,000 rpm for $10 \mathrm{~min})$. Control incubations were also performed in the absence of hepatocytes to test the stability of PH46A $(5 \mu \mathrm{M})$.

For the metabolite identification phase, PH46A samples $(20 \mu \mathrm{M}$ in water) were incubated for 240 min only in DMEM $(1 \mathrm{~mL})$ with sampling at 0 and $240 \mathrm{~min}$ and terminated by an equal volume of cold acidified $\mathrm{MeOH}$ containing IS.

The metabolic competence of the cells $\left(1 \times 10^{6}\right.$ cells $\left./ \mathrm{mL}\right)$ was assessed in parallel following incubations of $\left[{ }^{14} \mathrm{C}\right]-7$-EC $(10 \mu \mathrm{M}$ in DMEM) and $\left[{ }^{14} \mathrm{C}\right]$-testosterone $(150 \mu \mathrm{M}$ in $\mathrm{ACN})$ in DMEM $(1 \mathrm{~mL})$ as positive control. Aliquots $(100 \mu \mathrm{L})$ were taken and terminated at different time points and the samples were prepared for analysis as above. The remaining samples $(400 \mu \mathrm{L})$ were mixed with the appropriate termination reagent.

\section{Analytical methods validation \& determination of PH46A in culture medium}

An LC-MS/MS method for detection and quantification of PH46 in dosing solutions and post-incubation supernatants was developed, and
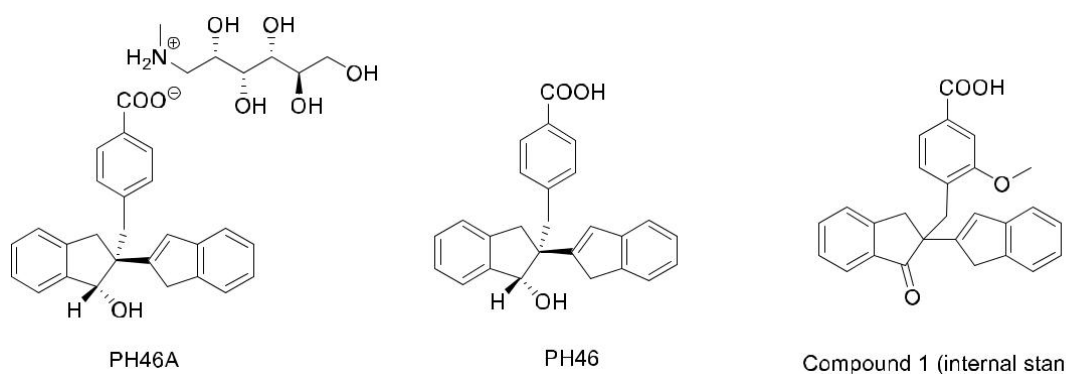

Figure 1: Chemical structures of $\mathrm{PH} 46 \mathrm{~A}, \mathrm{PH} 46$ and Compound 1 (internal standard). 
Citation: Zhang T, Scalabrino G, Frankish N, Sheridan H (2018) Bioactive Indanes: Comparative in vitro Metabolism Study of PH46A, a New Potential Anti-inflammatory Agent and Biosynthesis of its Primary Metabolite PH132. J Drug Metab Toxicol 9: 239. doi:10.4172/2157-7609.1000239

the following parameters (assay linearity, intra-batch assay accuracy and precision) were assessed.

Assay linearity: A series of calibration standards (CS) were prepared in DMEM containing PH46 over the target concentration range of $0.5-7.0 \mu \mathrm{M}$ at a minimum of 6 concentrations, and a fixed concentration of IS. Calibration curves were constructed from PH46: IS peak area response ratios plotted against the actual concentration of PH46 to determine the optimum regression parameters. The acceptance criteria was that the calculated concentration of $\mathrm{PH} 46$ for each standard from the calibration line should be within $100 \pm 15 \%$ of the actual amount in culture media $[100 \pm 20 \%$ at lower limit of quantification (LLOQ)]. At least $75 \%$ (and a minimum of 6 ) of the CS samples should meet the above criteria.

Intra-batch assay accuracy and precision: Replicate $(\mathrm{n}=6)$ quality control (QC) samples were prepared in DMEM containing PH46 at $0.5,1.2,2.6$ and $5.6 \mu \mathrm{M}$ and a fixed concentration of IS. The samples were extracted and analyzed, and the concentration of each replicate sample was determined from the calibration curve made above. The acceptance criteria at each level were that the intra-batch assay accuracy (the mean percentage determined concentration/actual concentration) should be within $100 \pm 15 \%(100 \pm 20 \%$ at LLOQ $)$ and the intra-batch assay precision (the coefficient of variation of the mean determined concentration) should be $\leq 15 \%$ at each concentration level $(\leq 20 \%$ at LLOQ).

Chromatographic conditions: The culture medium samples were analyzed by LC-MS/MS and the concentration levels of PH46 in the samples were determined using IS. The LC-MS analysis was performed on Perkin Elmer series 200 and AB Sciex API 3000. Ascentis Express C18 column $(75 \times 2.1 \mathrm{~mm}, 2.7 \mu \mathrm{m})$ with guard column (PreFrit Filter, $6.4 \times 1.6 \mathrm{~mm}, 0.5 \mu \mathrm{m})$ was utilized with mobile phases: A [MeOH/acetic acid (AA), 100/0.2, v/v] and B (water/AA, 100/0.2, v/v). The pump gradient (A/B) was: $0 \mathrm{~min}$ (60/40), $2 \mathrm{~min}(80 / 20), 4 \mathrm{~min}$ (80/20), 4.5 $\min (100 / 0), 4.7 \mathrm{~min}(60 / 40), 4.9 \mathrm{~min}(100 / 0)$ and $8.0 \mathrm{~min}(60 / 40)$ with flow rate of $0.3 \mathrm{~mL} / \mathrm{min}$. The column and autosampler temperatures were $60^{\circ} \mathrm{C}$ and $4{ }^{\circ} \mathrm{C}$ respectively. The injection volume was $1-20 \mu \mathrm{L}$ (as required for sensitivity) with run time of 10 min (taking into account autosampler cycle time)]. The mass spectrometer parameters were Turbo Ion Spray ionisation negative mode, ion spray temperature of $550^{\circ} \mathrm{C}$, probe position of $3 \mathrm{~mm}(\mathrm{X}) \& 7 \mathrm{~mm}(\mathrm{Y})$, standard API3000 all nitrogen gases, settling time of $5 \mathrm{msec}$ and pause time of $5 \mathrm{msec}$.

Calculations \& run acceptability: Integration of PH46 and IS peaks was done by a smoothing factor of 2 and the peak area ratio of PH46:IS for each CS, QC and test samples were calculated. A calibration curve was constructed by plotting the peak area ratio of the calibrations standards $v s$. the concentration of each test item in matrix and determine the linear regression parameters of the curve, using a weighting factor of $1 / \mathrm{x}^{2}\left(1 /\right.$ concentration $\left.^{2}\right)$. The concentration of $\mathrm{PH} 46$ in QC samples and test samples was determined by interpolation of the peak area ratios from the calibration curve. At least $75 \%$ of CS samples must back-calculate to within $100 \pm 15 \%$ of the actual concentrations $(100 \pm 20 \%$ at the lower limit of quantification). At least $66 \%$ of QC samples must be within $100 \pm 15 \%$ of the actual concentration, including at least one at each level.

Each batch contained double blank sample (absence of both PH46A and IS), single blank sample (absence of PH46A and presence of IS), CS samples, QC samples and test samples. The CS samples were prepared at $0.5,1.3,1.8,2.3,2.7,3.2,3.7,4.5,5.0,6.2$ and $7.0 \mu \mathrm{M}$, which were injected at the start of each batch. Duplicate LLOQ $(0.5 \mu \mathrm{M})$ and upper limit of quantification (ULOQ) $(7.0 \mu \mathrm{M})$ was also made to minimize the risk of not achieving a valid standards at LLOQ or ULOQ levels. Only one of the CS samples, at each concentration level, was employed in the assay calibration line. QC samples were prepared in duplicate at least at 1.2, 2.6 and $5.6 \mu \mathrm{M}$. For the analysis of test samples groups of one at each of low, medium and high concentrations of the QC samples were analyzed after the calibration line and after study samples. Where QC samples are prepared in triplicate, additional groups of QC samples should be interspersed within the test samples. Study samples were run bracketed by groups of QC samples. The test samples were analyzed from low to high concentrations. Under normal assay conditions two reconstitution solvent samples $\mathrm{MeOH} /$ water/AA (50/50/0.2, v/v/v) samples were used after the top standard and high QC samples to avoid significant carryover.

\section{HPLC analysis of supernatants from $\left[{ }^{14} \mathrm{C}\right]-7-\mathrm{EC} \&\left[{ }^{14} \mathrm{C}\right]-$ testosterone incubations}

$\left[{ }^{14} \mathrm{C}\right]-7-\mathrm{EC},\left[{ }^{14} \mathrm{C}\right]-$ Testosterone and their corresponding metabolites present in the post-incubation supernatants were resolved by HPLC analysis performed on Waters 2695 separations module with Waters 486 Tunable absorbance detectors and Perkin Elmer Radiomatic ${ }^{\mathrm{TM}}$ Floone ${ }^{\oplus}$ Beta Scintillation Analyser (Model 150TR). For $\left[{ }^{14} \mathrm{C}\right]-7-\mathrm{EC}$ incubation, Hypersil BDS C8 column $(250 \times 4.6 \mathrm{~mm}, 5 \mu \mathrm{m})$ was used with mobile phases: A [tetrabutylammonium phosphate monobasic in water $(5 \mathrm{mM}) / \mathrm{AA}, 100 / 1, \mathrm{v} / \mathrm{v}]$ and $\mathrm{B}(\mathrm{ACN} / \mathrm{AA}, 100 / 1, \mathrm{v} / \mathrm{v})$. The pump gradient (A/B) was: $0 \mathrm{~min}(94 / 6), 10 \mathrm{~min}(49 / 51), 20 \mathrm{~min}$ (49/51), $25 \mathrm{~min}$ (94/6) and $35 \mathrm{~min}(94 / 6)$ with flow rate of $1 \mathrm{~mL} / \mathrm{min}$. The column and auto sampler temperatures were ambient and $10^{\circ} \mathrm{C}$, respectively. The injection volume was $0.1 \mathrm{~mL}$ with run time of $35 \mathrm{~min}$. UV wavelength $320 \mathrm{~nm}$ was used with data captured by Labsystems Atlas 2002 R1. For $\left[{ }^{14} \mathrm{C}\right]$-testosterone incubations, Novapak C18 column $(150 \times 3.9 \mathrm{~mm}, 4 \mu \mathrm{m})$ and pre-Column Novapak C18 $(20 \times$ $3.9 \mathrm{~mm}, 4 \mu \mathrm{m})$ were used with mobile phases: A (water), B $(\mathrm{MeOH})$ and $\mathrm{C}(\mathrm{ACN})$. The pump gradient $(\mathrm{A} / \mathrm{B} / \mathrm{C})$ was: $0 \mathrm{~min}(75 / 25 / 0), 40$ $\min (30 / 64 / 6), 45 \min (75 / 25 / 0)$ and $55 \mathrm{~min}(75 / 25 / 0)$, with flow rate of $1 \mathrm{~mL} / \mathrm{min}$. The column and autosampler temperatures were $50^{\circ} \mathrm{C}$ and $10^{\circ} \mathrm{C}$, respectively. The injection volume was $0.1 \mathrm{~mL}$ with run time of $55 \mathrm{~min}$. UV wavelength of $240 \mathrm{~nm}$ was used with data captured by Labsystems Atlas 2002 R1.

\section{Calculation of intrinsic clearance}

Intrinsic clearance values were calculated using the following equation. The physiological parameters (no. of hepatocytes per $g$ of liver \& g of liver per $\mathrm{kg}$ of bodyweight) used were: $120 \times 10^{6} \& 40$ for Rat [25], $240 \times 10^{6}$ [26] \& 32 [27] for dog, $135 \times 10^{6} \& 25$ for monkey [28] and $120 \times 10^{6} \& 26$ for human [25].

$$
\begin{aligned}
\text { Intrinsic Clearance }= & \frac{0.693}{\text { invitro } \mathrm{T}_{1 / 2}(\mathrm{~min})} \times \frac{\text { mLincubation }}{\text { no. of hepatocytes }} \\
& \times \frac{\text { no. of hepatocytes }}{\text { g of liver weight }} \times \frac{\text { g of liver weight }}{\text { kg of body weight }}
\end{aligned}
$$

Where in vitro $\mathrm{T}_{1 / 2}$ is estimated using the gradient $(\mathrm{k})$ of the line of the logarithmic mean \% parent compound remaining against, and the equation: in vitro $\mathrm{T}_{1 / 2}=0.693 / \mathrm{-k}$.

\section{Analytical method for metabolite identification}

The metabolite profiling investigation following incubation was performed by LC-MS/MS analysis using Shimadzu LCMS-IT-TOF mass spectrometer and Shimadzu Prominence HPLC with pumps (LC20ADXR), degasser (DGU-20A3), autosampler (SIL-20ACXR), column 
Citation: Zhang T, Scalabrino G, Frankish N, Sheridan H (2018) Bioactive Indanes: Comparative in vitro Metabolism Study of PH46A, a New Potential Anti-inflammatory Agent and Biosynthesis of its Primary Metabolite PH132. J Drug Metab Toxicol 9: 239. doi:10.4172/2157-7609.1000239

oven (CTO-20ACXR), DAD (SPDM20AXR) and communications module (CBM-20AXR).

LC conditions 1 (LC1): Agilent EC-C18 column $(50 \times 2.1 \mathrm{~mm}$ $1.7 \mu \mathrm{m}$ ) was used with mobile phases: A (water/AA, 100/0.2, v/v) and $\mathrm{B}(\mathrm{MeOH} / \mathrm{AA}, 100 / 0.2, \mathrm{v} / \mathrm{v})$. The pump gradient $(\mathrm{A} / \mathrm{B})$ was: $0 \mathrm{~min}$ (70/30); $11 \mathrm{~min}(0 / 100) ; 12 \mathrm{~min}(0 / 100) ; 13 \mathrm{~min}(70 / 30)$ and $15 \mathrm{~min}$ $(70 / 30)$ with flow rate of $0.3 \mathrm{~mL} / \mathrm{min}$. The column and autosampler temperatures were $60^{\circ} \mathrm{C}$ and $4^{\circ} \mathrm{C}$, respectively with diode array detector (DAD) range of $190-800 \mathrm{~nm}$.

LC conditions 2 (LC2): Kinetix PFP column $(50 \times 2.1 \mathrm{~mm}, 1.7 \mu \mathrm{m})$ was used with mobile phases: $\mathrm{A}$ (water/AA, 100/0.2, v/v) and B (MeOH/ AA, 100/0.2, v/v). The pump gradient (A/B) was: 0 min (90/10); $11 \mathrm{~min}$ $(0 / 100) ; 12 \mathrm{~min}(0 / 100) ; 13 \mathrm{~min}(90 / 10)$ and $15 \mathrm{~min}(90 / 10)$ with flow rate of $0.3 \mathrm{~mL} / \mathrm{min}$. The column and autosampler temperatures were $60^{\circ} \mathrm{C}$ and $4^{\circ} \mathrm{C}$ with DAD range of $190-800 \mathrm{~nm}$.

MS conditions: Electrospray ionisation (ESI) was selected with both curved desolvation line and block temperatures at $230^{\circ} \mathrm{C}$. The nebulising gas $\left(\mathrm{N}_{2}\right)$ flow was $1.5 \mathrm{~L} / \mathrm{min}$ with collision-induced dissociation gas of Argon and drying gas on. The data acquisition in both positive and negative mode was achieved using automatic gain control (ASC $10 \mathrm{e}^{6}$ ) and the Q (low mass cut-off) value was 0.251 (45 $\mathrm{kHz}$ ) with precursor ion isolation of $3 \mathrm{amu}$.

Accurate mass measurement was used to differentiate between potential metabolites with the same nominal mass. The accurate mass error ( $\mathrm{ppm}$ ) was calculated from a comparison of the measured mass with the theoretical mass for a suggested assignment. A low accurate mass error $(<5 \mathrm{ppm})$ supports the assignment. Conversely a large accurate mass error would refute the assignment. Metabolite screening software (Met ID Solutions version 1.2) was also used to aid the identification of potential metabolites. Analysis of T0 sample was used to subtract background matrix for each species. A media control sample was used to indicate any non-metabolic changes to PH46. The output of the software screening was reviewed and possible metabolites investigated further manually.

\section{Screening of enzymes \& microsomes against PH46 \& LC-MS detection}

Almac's selectAZyme panels of 18 recombinant human liver P450 monooxygenases, 40 recombinant microbial P450 monooxygenases (self-sufficient cytochrome $\mathrm{P} 450$ enzymes were heterologously expressed in E. coli) and 4 different microsomes were screened against PH46 using a glucose dehydrogenase based cofactor regeneration system. Reactions were analyzed after $4 \mathrm{~h}$ and overnight reaction time by newly developed LC-MS method, LC3, in both positive \& negative modes, and the tentative metabolite hits were further analyzed via MS/MS experiments. The details of the screening procedure and the corresponding tentative metabolite screening results are provided in Supplementary Table S1.

LC conditions 3 (LC3) (for screening purpose only): Luna C18 $(50 \times 2 \mathrm{~mm}, 3 \mu \mathrm{m})$ was used with mobile phases: A (water/AA, 100/0.1, $\mathrm{v} / \mathrm{v})$ and $\mathrm{B}(\mathrm{ACN} / \mathrm{AA}, 100 / 0.1, \mathrm{v} / \mathrm{v})$. The pump gradient $(\mathrm{A} / \mathrm{B})$ was: 0 $\min (70 / 30), 5 \mathrm{~min}$ (35/65), $5.10 \mathrm{~min}(0 / 100), 7 \mathrm{~min}(0 / 100), 7.10 \mathrm{~min}$ $(70 / 30)$ and $10 \mathrm{~min}(70 / 30)$ with flow rate of $1 \mathrm{~mL} / \mathrm{min}$. The column temperature was ambient temperature.

LC conditions 4 (LC4): It was further developed for all further analysis throughout the biotranformation study, due to the most accurate match of the relative retention times of the metabolites observed in the metabolism study. Kinetix C18 $(50 \times 4.6 \mathrm{~mm}, 2.6 \mu \mathrm{m})$ was used with mobile phase: A (water/AA, 100/0.2, v/v) and B (MeOH/ $\mathrm{AA}, 100 / 0.2, \mathrm{v} / \mathrm{v})$. The pump gradient $(\mathrm{A} / \mathrm{B})$ was $0 \min (70 / 30), 11 \mathrm{~min}$ (0/100), $12 \mathrm{~min}$ (0/100), $13 \mathrm{~min}$ (70/30) and $15 \mathrm{~min}$ (70/30) with flow rate of $0.5 \mathrm{~mL} / \mathrm{min}$. The column temperature was $60^{\circ} \mathrm{C}$.

MS conditions: AB Sciex QQQ 365; Scan type: Q1 MS; polarity: positive/negative; ion source: turbo spray; mass range: 100-700; NEB 8; CUR: 8; IS: 4200; TEM: 300; DP: 46; FP: 180; EP: 9.

\section{Scale-up production of PH132 via selected bio-oxidation system and characterization methods}

The procedure outlined below was performed on $500 \mathrm{~mL}$ scale and total of $12 \times 500 \mathrm{~mL}$ reactions were conducted. $\mathrm{KH}_{2} \mathrm{PO}_{4}$ buffer $(100 \mathrm{mM}, 500 \mathrm{~mL})$ were prepared containing $\mathrm{MgCl}_{2}(5 \mathrm{mM})$, with $\mathrm{pH}$ adjustment to 7.4 using $\mathrm{KOH}$ solution. $437.5 \mathrm{~mL}$ of such buffer was then transferred into $2 \mathrm{~L}$ Erlenmeyer flask, followed by additions of Glucose $(3.6 \mathrm{~g})$ and GDH $(2 \mathrm{~g})$. The resulting mixture was gently stirred until complete dissolution, followed by the addition of $1 \mathrm{~mL}$ of PH46 stock solution (262 mM in DMSO) and $12.5 \mathrm{~mL}$ of RLM. The reaction was started with the addition of nicotinamide adenine dinucleotide phosphate Na-salt solution $(40 \mathrm{mM}, 50 \mathrm{~mL})$ and was left shaken overnight at $37^{\circ} \mathrm{C}$ at $200 \mathrm{rpm}$. The flasks were "closed" with a punctured tin foil to allow for oxygen transfer. ACN $(125 \mathrm{~mL})$ was added to quench each reaction, and the resulting solids (from proteins precipitation) were removed by centrifugation at $8000 \mathrm{rpm}$ for $10 \mathrm{~min}$. The residual solution was analyzed by LC-MS method using LC4 to determine conversions and subsequently prepared for sold phase extraction (SPE) and prep-HPLC purification.

SPE: A $60 \mathrm{~mL}$ Strata-X (33 u, polymeric reverse phase) tube was initially washed with $\mathrm{MeOH}(150 \mathrm{~mL})$ and equilibrated with water $(300$ $\mathrm{mL})$, followed by sample loading $(1500 \mathrm{~mL}$ of three reactions for the column). The flow through and the water washes were collected and analyzed for the desired product by HPLC. After sample loading, the tube was subsequently washed with water $(300 \mathrm{~mL})$. Before the tube became dry, it was wetted with $\mathrm{MeOH}$. $\mathrm{MeOH}$ was incubated on the column for $5 \mathrm{~min}$ without flow. The material was subsequently eluted with $\mathrm{MeOH}(150 \mathrm{~mL})$ at minimum flow. More $\mathrm{MeOH}$ was used for the complete elution, which was checked by HPLC. All fractions were combined and diluted to a $20 \% \mathrm{MeOH}$ solution with water for the next step, prep-HPLC purification.

Prep-HPLC purification was performed on Luna semi prep-HPLC column $(250 \times 30 \mathrm{~mm}, 10 \mu \mathrm{m})$ with $750 \mathrm{~mL}$ of sample (containing $300 \mathrm{mg}$ of crude material after dilution) applied to the column via an external pump operating at $9 \mathrm{~mL} / \mathrm{min}$. The isocratic mobile phase system, ACN/Water/AA (40/60/0.1, v/v/v), was used with flow rate of $42.5 \mathrm{~mL} / \mathrm{min}$ for each injection $(600 \mathrm{mg}$ of crude were created in total 2 injections). The total run-time was $70 \mathrm{~min}$. The purity of the fractions was then tested by LC4 and the fractions containing PH132 with purities $>95 \%$ were pooled and concentrated to dryness by vacuo at $37^{\circ} \mathrm{C}$. ACN was used to azeotroph any residual water. The fractions with less purity were combined and purified further.

NMR spectra were recorded on Bruker DPX-600 and Bruker DPX400 instruments operating at $400.1 \mathrm{MHz}$ and $600.1 \mathrm{MHz}$ for ${ }^{1} \mathrm{H}$ NMR; 100.6 MHz and $150.9 \mathrm{MHz}$ for ${ }^{13} \mathrm{C}-\mathrm{NMR}$ and calibrated using residual undertreated solvent as an internal reference $\left(\mathrm{CHCl}_{3} @ \delta 7.26 \mathrm{ppm}{ }^{1} \mathrm{H}\right.$ NMR, $\delta=77.16{ }^{13} \mathrm{C}$ NMR; DMSO-d6@ $\delta=5.32$ ppm ${ }^{1} \mathrm{H}$ NMR, $\delta=39.51$ ppm ${ }^{13} \mathrm{C}$ NMR). The following abbreviations were used to explain ${ }^{1} \mathrm{H}$ NMR multiplicities: $\mathrm{s}=$ singlet, $\mathrm{d}=$ doublet, $\mathrm{t}=$ triplet, $\mathrm{m}=$ multiplet, 
Citation: Zhang T, Scalabrino G, Frankish N, Sheridan H (2018) Bioactive Indanes: Comparative in vitro Metabolism Study of PH46A, a New Potential Anti-inflammatory Agent and Biosynthesis of its Primary Metabolite PH132. J Drug Metab Toxicol 9: 239. doi:10.4172/2157-7609.1000239

br=broad. NMR spectra were analyzed with Bruker Toppsin 3.5pl7 software. High-resolution mass spectra (HRMS) were measured on a Micromass LCT electrospray TOF instrument with a WATERS 2690 autosampler and methanol as carrier solvent. Data analysis was performed using MassKynx software.

\section{Results and Discussion}

\section{Assay linearity, intra-batch assay accuracy and precision}

It was found that regression analysis of the peak area ratios of PH46:IS against the amount of PH46 had demonstrated good linearity in culture medium over the range $0.5-7 \mu \mathrm{M}$ with a $1 / \mathrm{x}^{2}$ linear weighting. The determined concentrations for these standards $(0.50,1.25,1.75$, $2.25,2.69,3.23,3.74,4.49,4.99,6.24$ and $6.98 \mu \mathrm{M})$ met the acceptance criteria. The intra-batch accuracy and precision of the assay for PH46A in DMEM met the acceptance criteria for each concentration level $(0.50,1.24,2.64$ and $5.60 \mu \mathrm{M})$ with replicate $(\mathrm{n}=6)$. The actual results are giving in Supplementary Tables S2 and S3.

\section{Incubation of PH46A (5 $\mu \mathrm{M}$ ) with cryopreserved hepatocytes}

The hepatocyte viability assessment for all species was above $75 \%$ acceptance criterion with the viability values of $84.3 \%$ (male rat), 80.7\% (male dog), 78.0\% (male monkey), 76.4\% (mixed gender pooled human). Incubation of PH46A at $5 \mu \mathrm{M}$ with cryopreserved hepatocytes resulted in partial loss of $\mathrm{PH} 46$ in all four species at all-time points, except $\mathrm{T}=0 \mathrm{~min}$, over the time course of the incubation of $240 \mathrm{~min}$. This loss was not observed significantly during incubation of PH46A with DMEM, indicating that $\mathrm{PH} 46$ appeared to be stable over the time course under incubation conditions; however small portion $(\sim 10 \%)$ of PH46 loss was seen after 30 min of incubation in DEME, which was considered to be due to weak interaction between $\mathrm{PH} 46$ and amino acids present in DEME media.

The concentration of PH46 remaining at 240 min was found to be below LLOQ $(0.5 \mu \mathrm{M})$ following incubation with rat and human cryopreserved hepatocytes. The percentage of PH46 remaining at 240 min was $10.8 \%$ and $12.4 \%$ following incubation with dog and monkey hepatocytes, respectively. The results are presented in Table 1. The natural $\log (\ln )$ of the percentage of PH46 remaining was also calculated. The in vitro intrinsic clearance values following incubation at $5 \mu \mathrm{M}$ of PH46A ( $\mathrm{mL} / \mathrm{min} / \mathrm{kg}$ body weight) were also determined to be 93.1 (rat), 72.2 (dog), 30.0 (monkey) and 24.4 (human). The order of clearance for the species was $r a t>d o g>$ monkey $>$ human.

\section{Incubation of $\left[{ }^{14} \mathrm{C}\right]-7-\mathrm{EC}$ and $\left[{ }^{14} \mathrm{C}\right]$-testosterone with cryopreserved hepatocytes}

Incubations of cryopreserved hepatocytes with $\left[{ }^{14} \mathrm{C}\right]-7-\mathrm{EC}$ and $\left[{ }^{14} \mathrm{C}\right]$-testosterone resulted in partial or complete disappearance of parent compounds over $240 \mathrm{~min}$ incubation periods. In the case of $\left[{ }^{14} \mathrm{C}\right]-7-\mathrm{EC}, 3$ of the metabolites formed were identified in all species against authentic standards: 7-hydroxycoumarin (7-HC) (phase I), 7-HC glucuronide and 7-HC sulphate (phase II). For $\left[{ }^{14} \mathrm{C}\right]$-testosterone, the major metabolite $6 \beta$-hydroxytestosterone was identified against an authentic standard in all species. The above data indicates that all hepatocytes were intact and were suitable for the assessment of metabolism of PH46A.

\section{Metabolite profiling of PH46A in rat, dog, monkey and human hepatocytes}

Reference standard PH46 was analyzed first. Accurate mass measurement of the deprotonated molecular ion $\left(\mathrm{m} / z 381[\mathrm{M}-\mathrm{H}]^{-}\right)$ with retention time (RT) 7.9 min confirmed the formula $\mathrm{C}_{26} \mathrm{H}_{22} \mathrm{O}_{3}$. The corresponding protonated ion was not observed, which was believed to be due to loss of water in the mass spectrometer source resulting in the presence of the ion with $m / z 365[\mathrm{M}+\mathrm{H}]^{+}$. Two potential routes were considered as two potential fragment ion structures were possible for the fragment ions with $\mathrm{m} / z 261 \& 245$. Fragmentation resulting in the loss of the indanol moiety was supported by accurate mass measurement. A fragmentation pathway was postulated based on analysis of the free acid form (PH46) of PH46A (Figure 2).

The representative chromatograms and mass spectra are given in Supplementary Figure S1. Comparison of the fragment ions observed for PH46 and postulated metabolites was used to support metabolite identification. During the metabolite profiling study, PH46 and metabolites (M1-M5) were detected in the same species by LCMS analysis at 240 min under both LC1 and LC2 conditions, with the exception of M4 (Figure 3). A summary of metabolite detection by LC1 for each species and the corresponding UV chromatograms

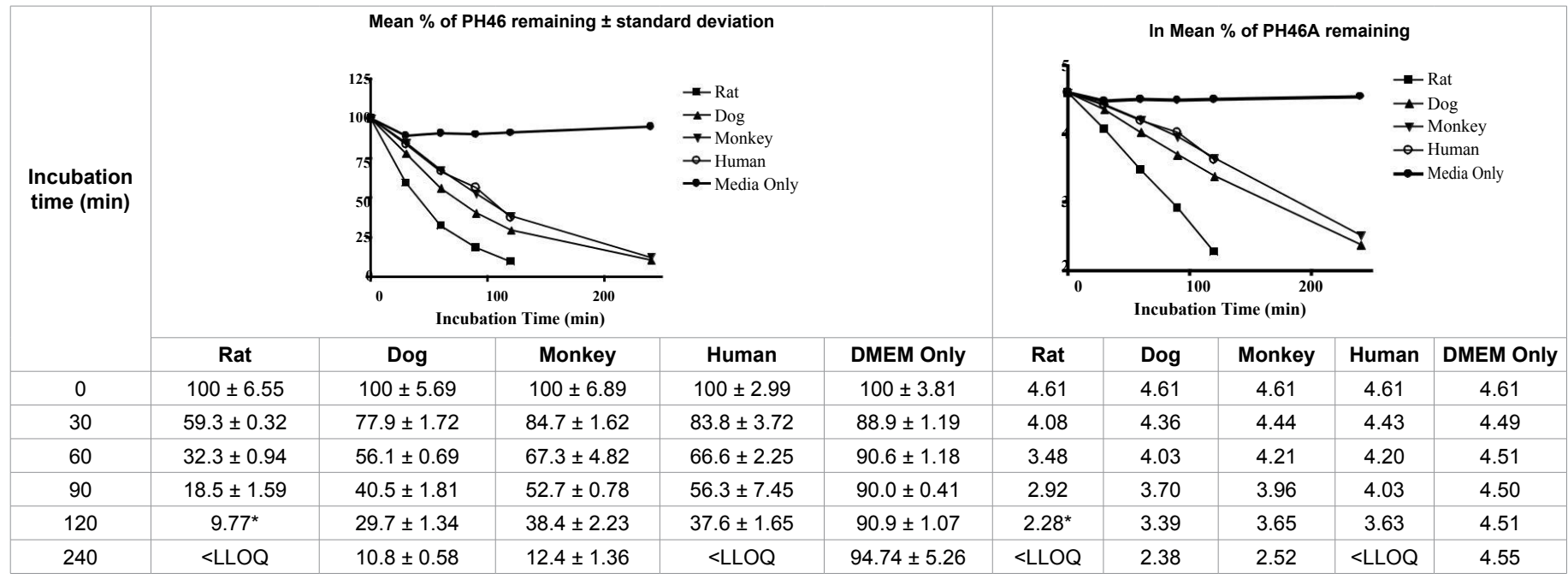

Table 1: Percentage (left) and In percentage (right) of PH46 remaining following incubation of PH46A with cryopreserved hepatocytes. <LLOQ:below the lower limit of quantification $(0.5 \mu \mathrm{M})$. In: natural log. Values obtained from 3 individual determinations with the exception of * which was determined from an individual determination, as the other two values were below the LLOQ. 
as representative are presented in Table 2 and Figure 4. The details of each metabolite's identification are described below and the related chromatograms and spectra of each metabolite are given in Supplementary Figures S1-S5.

PH46: The deprotonated ion $m / z 381\left([\mathrm{M}-\mathrm{H}]^{-}\right)$was observed at RT of $c a .8 .15 \mathrm{~min}$ (LC1) which was consistent with PH46. Accurate mass measurement confirmed the molecular formula as $\mathrm{C}_{26} \mathrm{H}_{22} \mathrm{O}_{3}$, and the product ions $\mathrm{m} / \mathrm{z} 261,245,135$ and 115 ([M-H]-) observed following fragmentation was consistent with $\mathrm{PH} 46$. A response for the positive ion $\mathrm{m} / \mathrm{z} 365\left([\mathrm{M}+\mathrm{H}]^{+}\right)$, formed by loss of water in the mass spectrometer source was also observed. This in-source fragmentation of the positive molecular ion was also consistent with the PH46 reference standard analysis and therefore was deemed to reinforce the identification of PH46 in hepatocyte incubates.

M1 (keto-PH46) with $m / z 379$ (RT ca. 8.7 min): The ion $\mathrm{m} / z$ $379\left([\mathrm{M}-\mathrm{H}]^{-}\right)$were observed for each species except monkey, which were postulated to correspond to keto- $\mathrm{PH} 46\left(\mathrm{C}_{26} \mathrm{H}_{20} \mathrm{O}_{3}\right)$ with RT of $8.7 \mathrm{~min}$ in the extracted ion chromatogram (EIC), and confirmation was obtained from accurate mass measurement. Fragmentation of the deprotonated molecular ion resulted in the product ions $\mathrm{m} / z 244 \& 135$ which was consistent with the fragmentation of the parent $\mathrm{PH} 46$ and thus supports the identification. A representative example is shown in Supplementary Figure S2.

M2 (PH46-OH, PH132) with $m / z 397$ (RT ca. 6.5 min): The ion $m / z 397\left([\mathrm{M}-\mathrm{H}]^{-}\right)$were observed for each species. Accurate mass

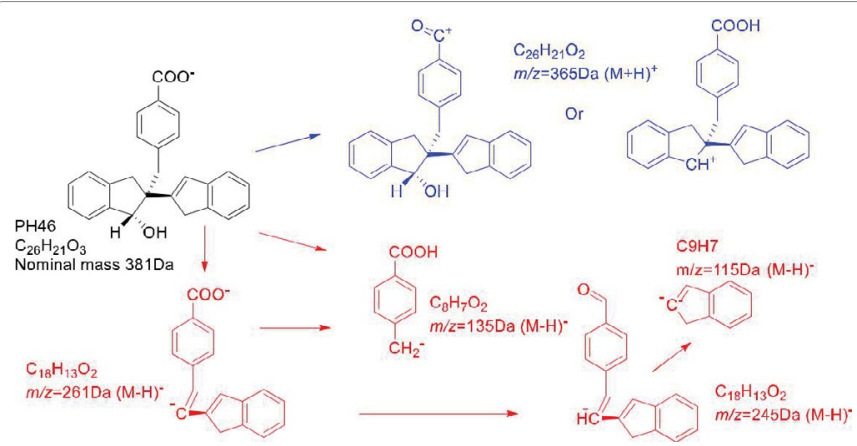

Figure 2: Postulated fragmentation pathway of $\mathrm{PH} 46$ reference standard by LC-MS analysis.

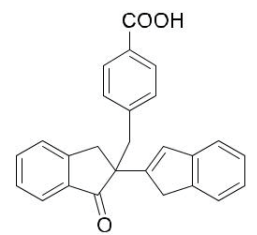

M1 $\mathrm{M} 1$
(keto-PH46)

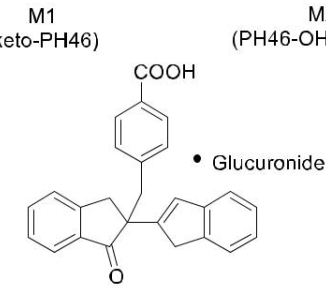

M4

(keto glucuronide-PH46)

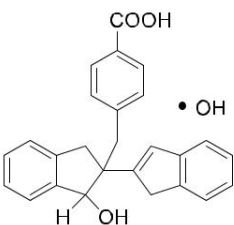

M2

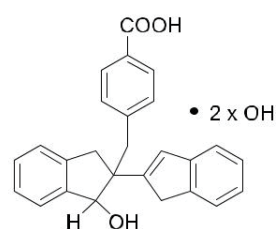

M3 $\mathrm{PH} 132)$

Figure 3: Molecular structures of five metabolites (M1-M5) of $\mathrm{PH} 46$ detected. measurement confirmed the formula $\mathrm{C}_{26} \mathrm{H}_{22} \mathrm{O}_{4}$ corresponding to PH132. Fragmentation of the deprotonated molecular ion resulted in the product ions $m / z 261$ and 135 . These fragment ions were consistent with PH46 fragmentation and suggested hydroxylation may occur on the indanol moiety (Supplementary Figures S3-S9). The spectra observed at 6.5 and $6.8 \mathrm{~min}$ were of low intensity which may be due to suppression by other ions such as $m / z 557$ which was not related to PH46 metabolism based on accurate mass observed.

M3 (PH46-diOH) with $m / z 413$ (RT ca. 6.3-7.5 min): The ion $\mathrm{m} / z$ $413\left([\mathrm{M}-\mathrm{H}]^{-}\right)$were observed in rat and the presence of peaks with RTs ca. 6.3-7.5 min in the EIC using LC2 indicated several isomers could be possible (Figure S5). Accurate mass measurement of the molecular ion confirmed the formula $\mathrm{C}_{26} \mathrm{H}_{22} \mathrm{O}_{5}$ corresponding to $\mathrm{PH} 46$-diOH. Fragmentation of the deprotonated molecular ion resulted in the product ions $m / z 395 \& 377$.

These fragments suggested the consecutive loss of two molecules of water from $\mathrm{PH} 46-\mathrm{diOH}$ and it was postulated that hydroxylation may occur on adjacent positions within a ring moiety. A structure for the fragment ion $\mathrm{m} / \mathrm{z} 395$ has been suggested but a mechanism by which a second loss of water from the ion $\mathrm{m} / z 395$ to yield ion $\mathrm{m} / z 377$ was not clear. It is envisaged that dihydroxylation could be possible on any of the 3 ring moieties, but it was not possible to confirm this from the product ions obtained by current study.

M4 (keto-glucuronide-PH46) with $m / z 555$ (RTs ca. 8.0-8.2 min): The ion $\left.m / z 555([\mathrm{M}-\mathrm{H}]]^{-}\right)$were observed for monkey and dog at $240 \mathrm{~min}$ by LC1 and for dog only by LC2, which were postulated to correspond to a ketone glucuronide of $\mathrm{PH} 46$. The presence of several peaks with RTs ca. 8.0-8.2 min in the EIC by LC2 indicates that several isomers (as with the glucuronide) are possible (Figure S6). Accurate mass measurement confirmed the formula $\mathrm{C}_{32} \mathrm{H}_{28} \mathrm{O}_{9}$. The deprotonated molecular ion fragmentation resulted in the product ion $\mathrm{m} / \mathrm{z} 379$ which were in turn fragmented resulting in product ions $\mathrm{m} / z 245 \&$ 135 , consistent with those formed following PH46 fragmentation. The spectra observed ca 8.0-8.2 min were of low intensity which may be due to suppression by other ions such as $m / z 521$.

\begin{tabular}{|c|c|c|c|}
\hline Species & RT (min) & $m / z\left([M-H]^{-}\right)$ & Postulated ID \\
\hline \multirow{4}{*}{ Rat } & 6.445 & 397 & M2 \\
\hline & 6.605 & 397 & M2 \\
\hline & 8.032 & 381 & $\mathrm{PH} 46$ \\
\hline & 8.556 & 379 & M1 \\
\hline \multirow{6}{*}{ Dog } & 6.439 & 397 & M2 \\
\hline & 6.608 & 557 & M5 \\
\hline & 6.874 & $\mathrm{~N} / \mathrm{A}$ & $\mathrm{N} / \mathrm{A}$ \\
\hline & 7.326 & 555 & M4 \\
\hline & 8.033 & 381 & $\mathrm{PH} 46$ \\
\hline & 8.556 & 379 & M1 \\
\hline \multirow{3}{*}{ Monkey } & 6.434 & 397 & M2 \\
\hline & 6.605 & 557 & M5 \\
\hline & 8.032 & 381 & $\mathrm{PH} 46$ \\
\hline \multirow{4}{*}{ Human } & 6.445 & 397 & M2 \\
\hline & $6.608 / 6.875$ & 557 & M5 \\
\hline & 8.032 & 381 & $\mathrm{PH} 46$ \\
\hline & 8.556 & 379 & M1 \\
\hline
\end{tabular}

Table 2: Summary of metabolite detected by LC-MS/MS (240 min, LC1) for each species (M1:keto-PH46; M2: PH46-OH (PH132); M4: keto-glucuronide-PH46; M5: glucuronide-PH46). 
(a)

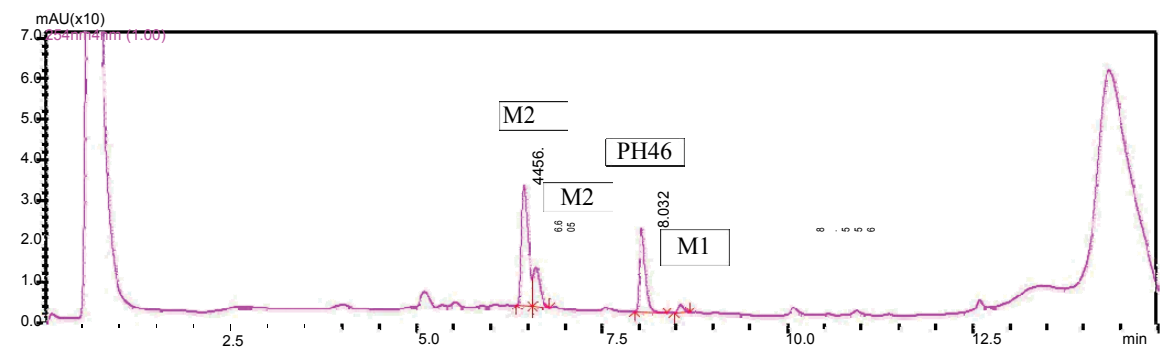

(b)

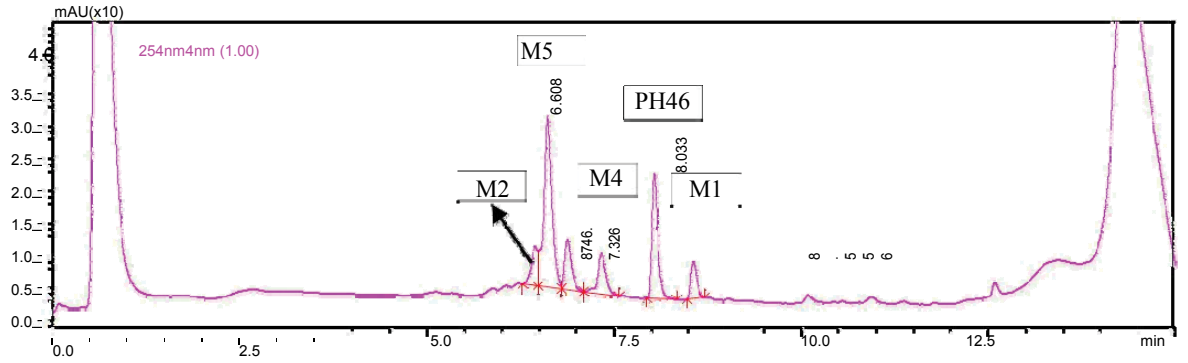

(c)

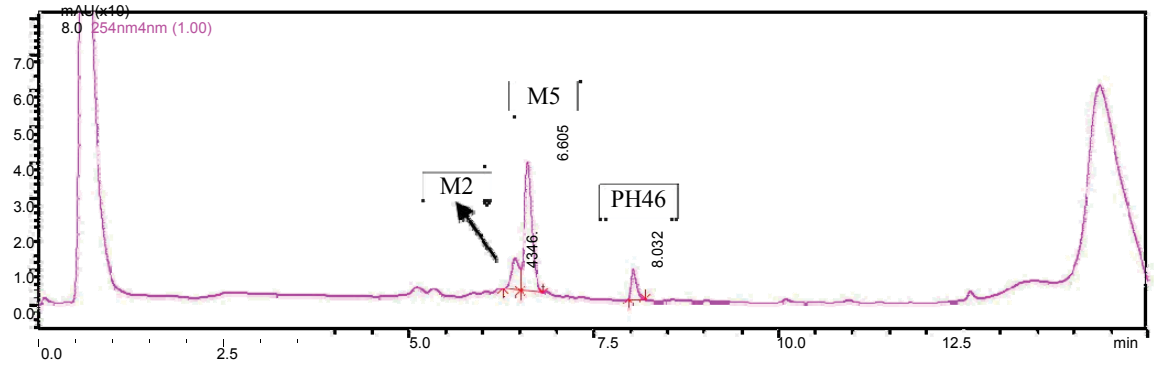

(d)

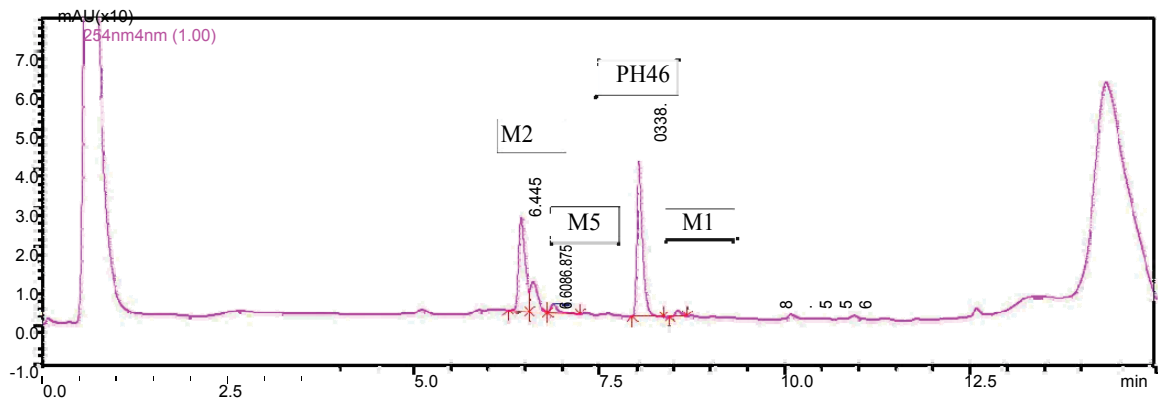

Figure 4: UV chromatograms (240 min, LC1) of LC-MS analysis for each species: rat (a), dog (b), monkey (c) and human (d).

M5 (glucuronide conjugate-PH46) with m/z 557 (RT ca. 7.3-7.7 min): The ion $\mathrm{m} / \mathrm{z} 557$ ([M-H]-) were observed for each species using both LC1 \& LC2. An example of rat sample analysis via LC2 is given in Figure S7. These were postulated to correspond to glucuronidePH46 and several unresolved peaks with RT ca. 7.3-7.7 min in the EIC indicated that several isomers were possible (Figure S8). These could be postulated to be the result of acyl migration and the analysis using LC1 afforded better resolution of the possible isomers (Figure S9). Accurate mass confirmed molecular formula $\mathrm{C}_{32} \mathrm{H}_{30} \mathrm{O}_{9}$ corresponding to glucuronide-PH46. Fragmentation of the deprotonated molecular ion resulted in ion $\mathrm{m} / \mathrm{z} 381$, which was further fragmented forming product ions consistent with those formed following fragmentation of PH46.

The results showed that $\mathrm{PH} 46$ was observed in all samples at 0 and 240 min and PH46A with hepatocytes resulted in the formations of
5 metabolites among various species: M1 (keto-PH46), M2 (PH46$\mathrm{OH}, \mathrm{PH} 132$ ), M3 (PH46-diOH), M4 (keto-glucuronide-PH46), M5 (glucuronide conjugate-PH46). LC-MS experiments via both LC1 and LC2 conditions provided the prominent and informative product ions for structural elucidation Table 3 and a summary of the qualitative metabolite formation following incubation is shown in Table 4. The postulated fragmentation pathways of all 5 metabolites are given in Figure 5.

The metabolic pathways shared similarities in all species tested. Two common metabolic routes to all species appeared to be phase I hydroxylation and phase II glucuronidation resulting in the formations of M2 and M5, respectively. In addition, oxidative transformation as minor metabolic pathway was detected in all species except monkey samples due to absence of M1 under both LC1 and LC2 conditions. $\mathrm{M} 3$ as unique metabolite was witnessed in rat hepatocyte sample. 
Citation: Zhang T, Scalabrino G, Frankish N, Sheridan H (2018) Bioactive Indanes: Comparative in vitro Metabolism Study of PH46A, a New Potential Anti-inflammatory Agent and Biosynthesis of its Primary Metabolite PH132. J Drug Metab Toxicol 9: 239. doi:10.4172/2157-7609.1000239

Page 8 of 14

\begin{tabular}{|c|c|c|c|}
\hline \multirow{2}{*}{ Component } & RT (min) & Nominal mass & \multirow{2}{*}{ Formula } \\
\cline { 2 - 4 } & LC1/LC2 & (Accurate mass) & Characteristic ions \\
\hline PH46 & $8.0 / 8.7$ & $381(381.1496)$ & C26H22O3 \\
\hline M1 & $8.7 / 9.2$ & $379(379.1339)$ & C26H20O3 \\
\hline M2 & $6.5 / 7.7$ & $397(397.1445)$ & C26H22O4 \\
\hline M3 & $3.8 / 6.3$ & $413(413.1394)$ & C26H22O5 \\
\hline M4 & $7.4 / 8.0$ & $555(555.1661)$ & C32H28O9 \\
\hline M5 & $6.7 / 7.5$ & $557(557.1817)$ & C32H30O9 \\
\hline
\end{tabular}

Table 3: Product ions of PH46 and its 5 metabolites observed by LC-MS. M1: keto-PH46; M2: PH46-OH; M3: PH46-diOH; M4: keto-glucuronide-PH46; M5: glucuronide conjugate-PH46.

\begin{tabular}{|c|c|c|c|c|c|c|c|}
\hline LC conditions & Species & PH46 & M1 & M2 & M3 & M4 & M5 \\
\hline \multirow{7}{*}{ LC1 } & PH46 reference & $\sqrt{ }$ & - & - & - & - & - \\
\hline & Rat & $\sqrt{ }$ & $\sqrt{ }$ & $\sqrt{ }$ & $\sqrt{ }$ & - & $\sqrt{ }$ \\
\hline & Dog & $\sqrt{ }$ & $\sqrt{ }$ & $\sqrt{ }$ & - & $\sqrt{ }$ & $\sqrt{ }$ \\
\hline & & & & & & & \\
\hline & Monkey & $\sqrt{ }$ & - & $\sqrt{ }$ & - & $\sqrt{ }$ & $\sqrt{ }$ \\
\hline & Human & $\sqrt{ }$ & $\sqrt{ }$ & $\sqrt{ }$ & - & - & $\sqrt{ }$ \\
\hline & DMEM & $\sqrt{ }$ & - & - & - & - & - \\
\hline \multirow{6}{*}{ LC2 } & $\mathrm{PH} 46$ reference & $\sqrt{ }$ & - & - & - & - & - \\
\hline & Rat & $\sqrt{ }$ & $\sqrt{ }$ & $\sqrt{ }$ & $\sqrt{ }$ & - & $\sqrt{ }$ \\
\hline & Dog & $\sqrt{ }$ & $\sqrt{ }$ & $\sqrt{ }$ & - & $\sqrt{ }$ & $\sqrt{ }$ \\
\hline & Monkey & $\sqrt{ }$ & - & $\sqrt{ }$ & - & - & $\sqrt{ }$ \\
\hline & Human & $\sqrt{ }$ & $\sqrt{ }$ & $\sqrt{ }$ & - & - & $\sqrt{ }$ \\
\hline & DMEM & $\sqrt{ }$ & - & - & - & - & - \\
\hline
\end{tabular}

Table 4: Summary of metabolite detection by LC-MS (240 min, LC1 \& LC2) for all species.

$\sqrt{ }$ Successfully detected.

- Not detected

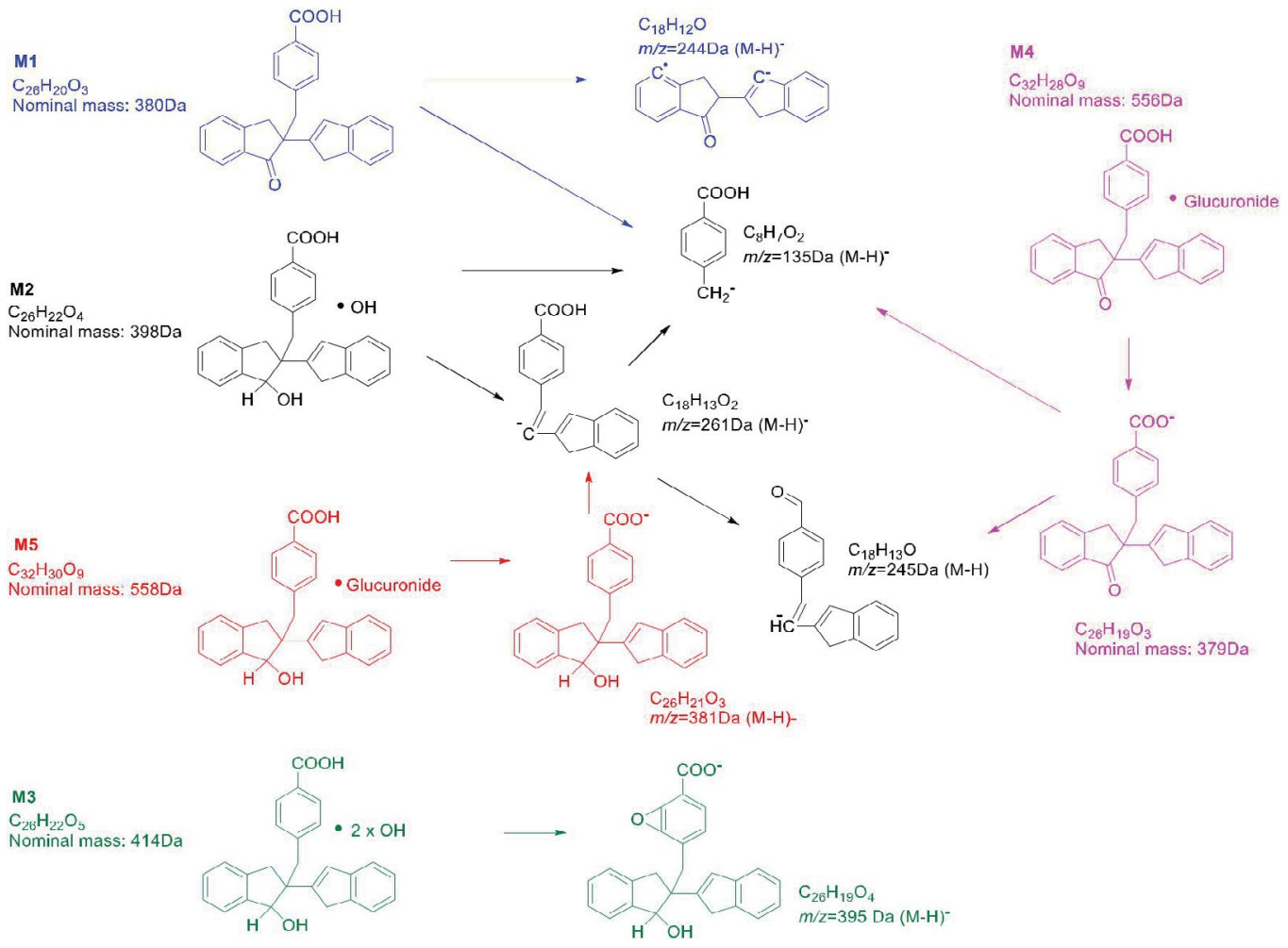

Figure 5: Postulated fragmentation pathways of observed metabolites M1 (blue), M2 (black), M3 (green), M4 (purple) and M5 (red) 
Furthermore, the observation of M4 in dog and monkey samples suggested that PH46 was susceptible to oxidation at hydroxyl functionality, followed by glucuronidation conjugation reaction. However, M4 was not detected in monkey samples under LC2. It is important to note that no major human-specific metabolite was found. Due to the qualitative nature of the current work, it was not possible to provide quantification of the metabolites detected. The relative quantification between $\mathrm{T} 0$ and the $\mathrm{T} 240$ in each species may be inferred from the UV chromatograms; however, the comparison of UV chromatograms was required with caution.

\section{Recombinant enzymes and microsomes screening}

The proposed route to the generation of the desired PH132 metabolite by biocatalysis involved initial screening using microbial $\mathrm{P} 450$ s, recombinant human liver P450s and microsomes, tentative hits were observed after $4 \mathrm{~h}$ with rat liver microsomes (RLM) ( 7\% conversion) and human Cyp-3 (Cyp2D6, 11\% conversion), human Cyp-4 (Cyp2C19, 11\% conversion) and human Cyp-13 (Cyp4A11, $\sim 25 \%$ conversion). The result of the RLM reaction after $24 \mathrm{~h}$ incubation via LC3 showed that the hydroxyl group in PH46 was unstable under the positive mode, with observations of $365 \mathrm{amu}\left(\mathrm{PH}_{46}-\mathrm{H}_{2} \mathrm{O}\right)$ and 381 $\mathrm{amu}\left(\mathrm{PH} 132-\mathrm{H}_{2} \mathrm{O}\right)$ only (see chromatograms and spectra in Figure 6).

During the MS/MS experiments of the RLM sample against reference PH46, fragmentation patterns in both negative mode (135 \& $261 \mathrm{amu})$ and positive mode $(131,135,246$ \& $249 \mathrm{amu})$ were comparable to those of PH46. The presence of 397 amu under negative mode confirmed the existence of the metabolite PH132; while the detection of $381 \mathrm{amu}$ from the positive mode allowed significant insight into the structure of $\mathrm{PH} 132$, which suggested that the $\mathrm{OH}$-group was attached onto the aromatic ring within the indene system (Figure 7). The corresponding chromatograms of the MS/MS experiments are shown in Supplementary Figures S10 and S11.
The identity of PH132 generated from the biotransformation screening was confirmed by a series of spiking experiments using LC4 method, including spiking against the in vitro metabolism hepatocyte samples [rat or human hepatocytes $(6 \mu \mathrm{g} / \mathrm{ml})$ spiking with the bio catalytic screening reaction samples being 10 fold more concentrated], and cross spiking between the RLM and Cyps screening samples (same concentration). The EIC at 397 amu was used for clear comparison. The details of these spiking experiments results are provided in Supplementary Figures S12-S17.

Two other tentative metabolites were also observed, $\mathrm{PH} 46-\mathrm{OH}$ ' in one human Cyp-9 (2C9) sample and $\mathrm{PH} 46-\mathrm{diOH}$ in various microbial Cyp samples (Figure 6). In the incubation with Cyp 9 for $24 \mathrm{~h}$, two peaks with the desired mass of $381 \mathrm{amu}\left(\mathrm{PH} 132-\mathrm{H}_{2} \mathrm{O}\right)$ were observed in the positive mode LC3. The MS/MS experiment revealed that the fragmentation pattern of both peaks was very similar, which suggested one could be the desired metabolite PH132 and one being a different isomer, $\mathrm{PH} 46-\mathrm{OH}^{\prime}$. However, due to the low concentration, no further structural conclusion of PH46-OH'was made. The LC-MS and MS/ MS results are given in Supplementary Figures S18 and S19. In some Cyp samples, incubated with microbial P450 enzymes, the peak with $415 \mathrm{amu}$ was observed, being possibly metabolite M3 (PH46-diOH). However, upon further investigation of MS/MS experiments, the fragmentation pattern of the peak with $415 \mathrm{amu}$ had no similarity with that of either PH46 or PH132. It is possible that this observed peak had not originated from $\mathrm{PH} 46$, thus not being a metabolite. The relevant chromatograms are given in Supplementary Figures S20 and S21.

\section{Structure elucidation of metabolite PH132 by NMR \& HRMS}

PH132 was isolated with purity of $95 \%$ Rat liver microsomes bio catalytic systems were used in the subsequent scale-up production of PH132 metabolite. Upon reaction work up and purification, The combined samples (from 12 reactions) were dried for $2 \mathrm{~d}$ on a high

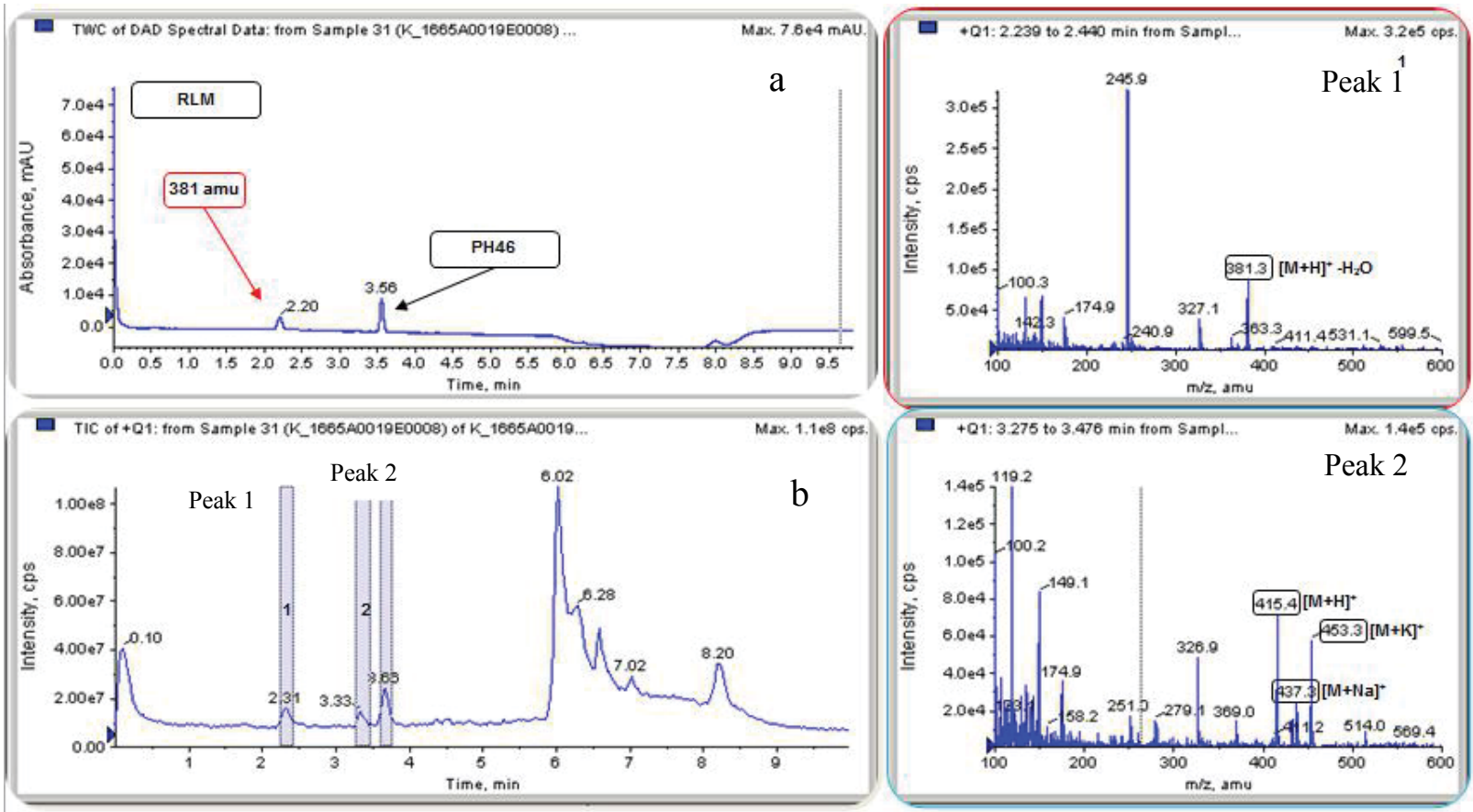

Figure 6: LC-MS total wave chromatogram (TWC, a) and total ion chromatogram (TIC, b) of PH46 incubated with rat liver microsomes (RLM) for 24 hours, with mass spectra (under positive mode) of peaks 1 and 2 . 

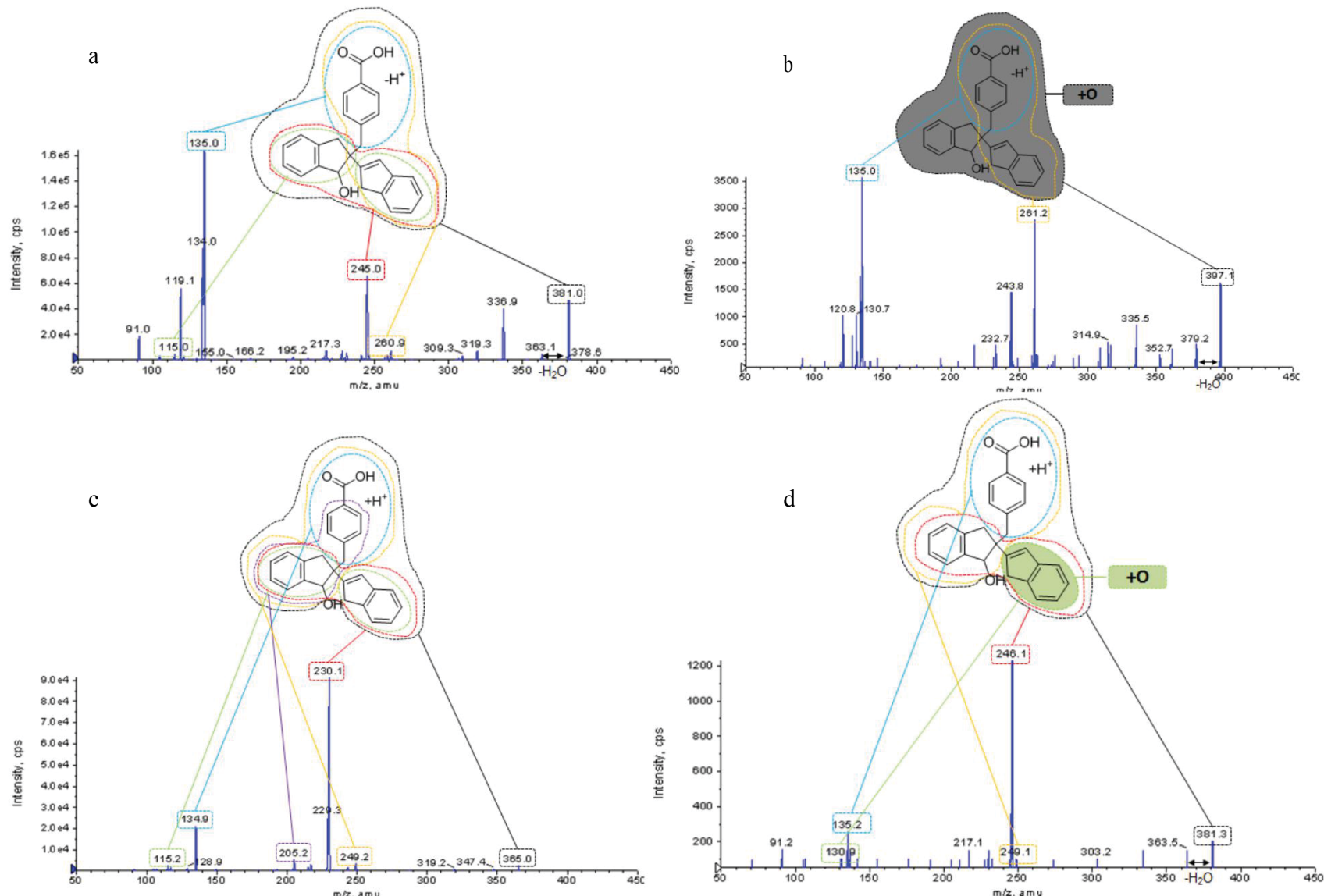

Figure 7: LC-MS/MS experiment results of $\mathrm{PH} 46$ (a) and $\mathrm{PH} 132$ (b) in negative mode, $\mathrm{PH} 46$ (c) and $\mathrm{PH} 132$ (d) in positive mode.

vacuum manifold and $64 \mathrm{mg}$ of PH132 (62\% yield) was obtained with purity of $95 \%$, as white powder. PH132 was characterized and its chemical structure was confirmed by NMR experiments using PH46 as reference for comparison (Figure 8). The molecular mass and absolute configurations were also monitored by HRMS and polarimetry. Representative NMR spectra are given below (Figures 9-13). The detailed NMR spectra and chromatograms are provided in Supplementary Figures S22-S28.

${ }^{1} \mathrm{H}$ and ${ }^{13} \mathrm{C}$ NMR data of $\mathrm{PH} 46$ were in agreement with the data we previously reported (Figures 9 and 10) [17]. The ${ }^{1} \mathrm{H}$ NMR spectrum of PH132 (Figure 11) shared similar spectral pattern as that of PH46. Structural assignments of $\mathrm{PH} 132$ were achieved with combinations of $1 \mathrm{D}\left({ }^{1} \mathrm{H},{ }^{13} \mathrm{C}\right.$, DEPTs \& NOESY $)$ and $2 \mathrm{D}\left({ }^{1} \mathrm{H}-{ }^{1} \mathrm{H}\right.$ COSY, HSQC, HMBC \& ROESY) NMR experiments.

The HSQC NMR spectrum of PH46 (blue) overlaying with the HSQC (red) and ${ }^{1} \mathrm{H}$ (green) NMR spectra of PH132 allowed the correlation of the assignments of most proton signals detected in the aromatic region in the ${ }^{1} \mathrm{H}$ spectrum of $\mathrm{PH} 132$ (Figure 12). The key feature in this analytical technique was the observation of the signal of the aromatic proton $\mathrm{H} 16$ of $\mathrm{PH} 132$ at $6.90 \mathrm{ppm}$ being a broad doublet. The ${ }^{1} \mathrm{H}-{ }^{1} \mathrm{H}$ COSY spectrum of $\mathrm{PH} 132$ confirmed the existence of the aromatic protons $\mathrm{H} 18, \mathrm{H} 19, \mathrm{H} 21, \mathrm{H} 22, \mathrm{H} 24$ and $\mathrm{H} 25$ from the correlations observed in Figure 13a.

The position of the double bond on the indene ring was further identified by ROSEY NMR experiments via $w$-coupling (NOE<smiles>[2H][C@@H]1c2ccccc2CC1(Cc1ccc(C(=O)O)cc1)[C@H]1C=Cc2ccccc2C1</smiles><smiles>C[C@@]1(O)[C@@H](O)c2ccccc2C[C@@]1(Cc1ccc(C(=O)O)cc1)C1=Cc2ccc(O)cc2C1</smiles>

Figure 8: Chemical structures of $\mathrm{PH} 46$ (left) and desired metabolite $\mathrm{PH} 132$ (right).

correlation) between the alkenic proton $\mathrm{H} 19$ at $6.90 \mathrm{ppm}$ being a board doublet and the aromatic proton $\mathrm{H} 15$ at $7.02 \mathrm{ppm}$ being a multiplet (Figure 13b). As a result, the position of the hydroxyl group of $\mathrm{PH} 132$ produced was determined to be at the $\mathrm{C} 17$ position. The chirality of PH132 was also measured by optical rotation. A negative value was obtained, which is consistent with PH46. Therefore, PH132 is chemically named as 4 -(((1'S,2'S)-1',6-dihydroxy-1',3'-dihydro$1 \mathrm{H}, 2$ 'H-[2,2'-biinden]-2'-yl)methyl)benzoic acid. The details of characterization of PH132 are: ${ }^{1} \mathrm{H}$ NMR (600.1 MHz, DMSO-d6) $\delta$ $2.70\left(1 \mathrm{H}, \mathrm{d}, J=13.31 \mathrm{~Hz}, \mathrm{CH}_{2}\right), 32.91\left(1 \mathrm{H}, \mathrm{d}, J=15.70 \mathrm{~Hz}, \mathrm{CH}_{2}\right), 2.94$ $\left(1 \mathrm{H}, \mathrm{d}, J=15.70 \mathrm{~Hz}, \mathrm{CH}_{2}\right), 3.16\left(1 \mathrm{H}, \mathrm{d}, J=13.31 \mathrm{~Hz}, \underline{\mathrm{CH}}_{2}\right), 3.36(1 \mathrm{H}, \mathrm{d}$, $\left.J=22.80 \mathrm{~Hz}, \mathrm{C}_{2}\right), 3.47\left(1 \mathrm{H}, \mathrm{d}, J=22.80 \mathrm{~Hz}, \mathrm{C}_{2}\right), 5.02(1 \mathrm{H}, \mathrm{d}, J=6.90$ $\mathrm{Hz}, \mathrm{C} \underline{\mathrm{HOH}}), 5.75(1 \mathrm{H}, \mathrm{d}, J=7.66 \mathrm{~Hz}, \mathrm{O} \underline{\mathrm{H}}), 6.27(1 \mathrm{H}, \mathrm{s}, \mathrm{C} \underline{\mathrm{H}}=\mathrm{C}), 6.58$ 


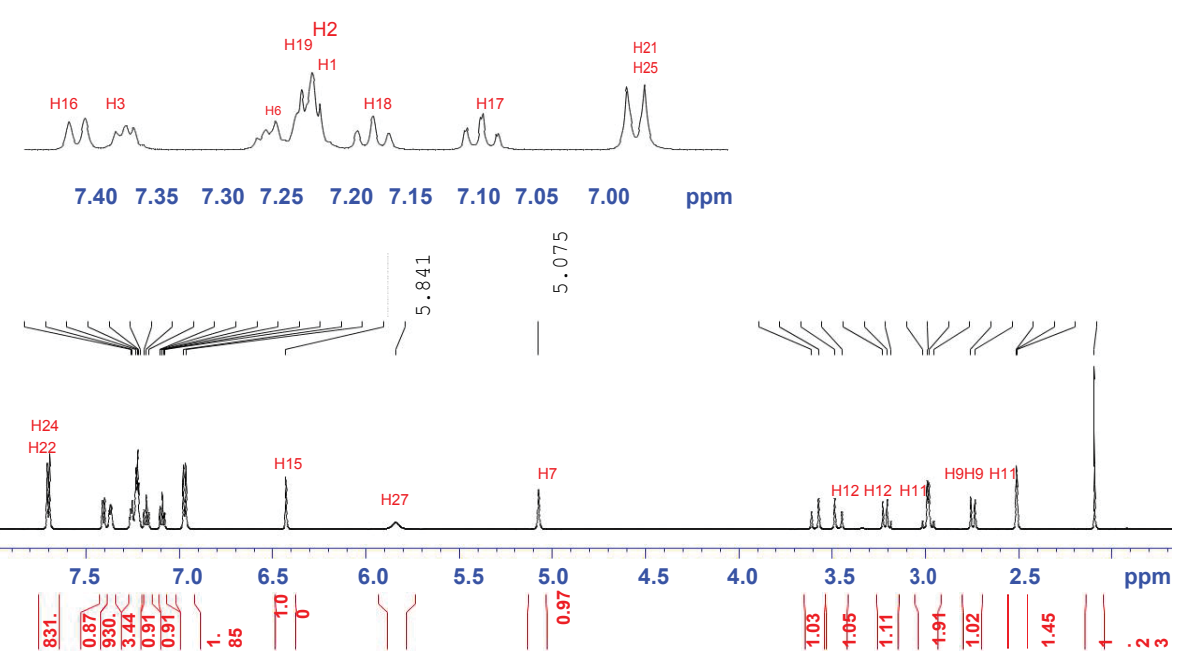

Figure 9: ${ }^{1} \mathrm{H}$ NMR spectrum of $\mathrm{PH} 46$ with atom assignments.
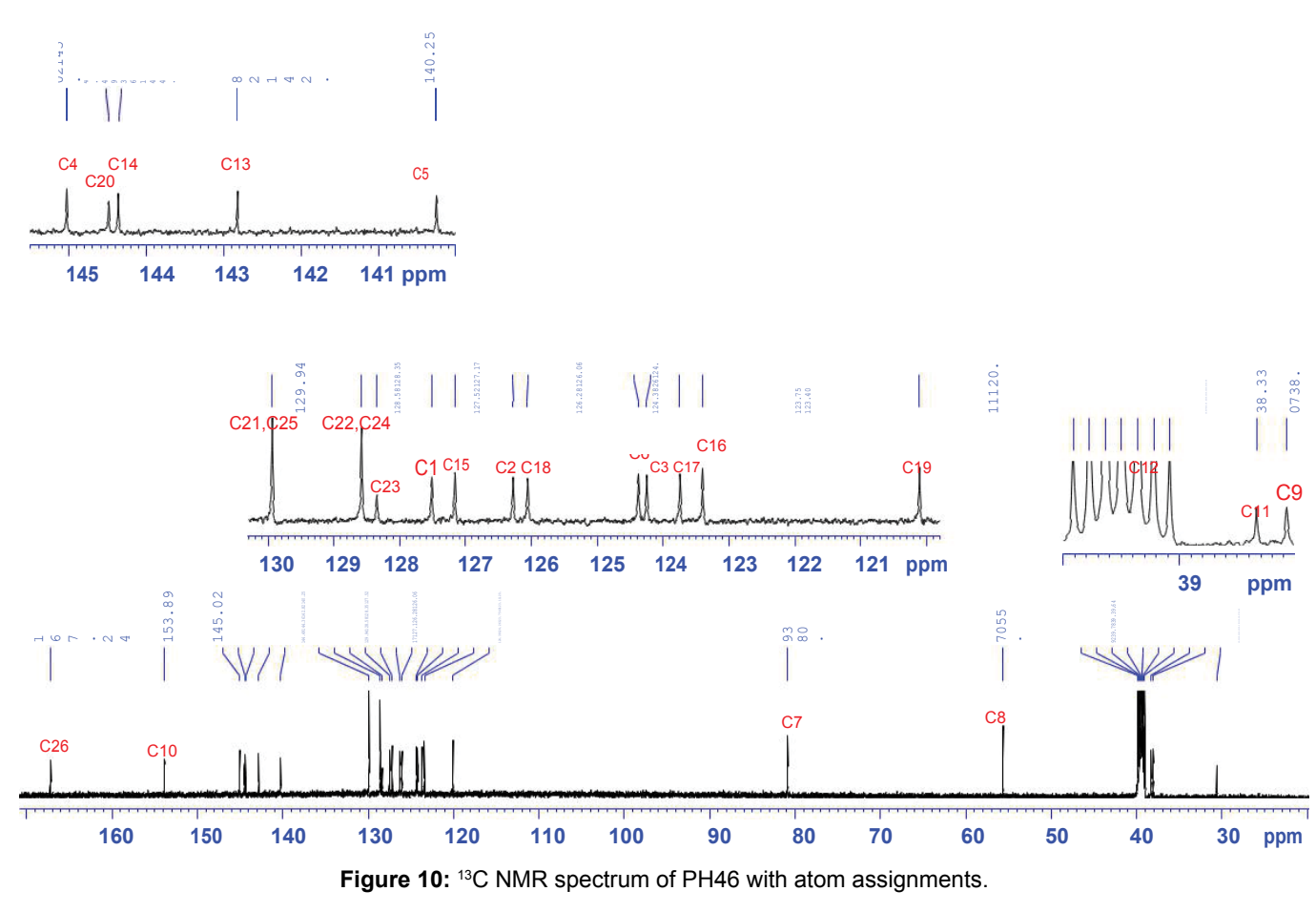

$\left(1 \mathrm{H}, \mathrm{dt}, J_{1}=2.74 \mathrm{~Hz}, J_{2}=8.23 \mathrm{~Hz}, \mathrm{Ar}-\underline{\mathrm{H}}\right), 6.85-7.36(8 \mathrm{H}, 4 \times \mathrm{m}, \mathrm{Ar}-\underline{\mathrm{H}})$, $7.69(2 \mathrm{H}, \mathrm{d}, J=8.28 \mathrm{~Hz}, \mathrm{Ar}-\underline{\mathrm{H}}) ;{ }^{13} \mathrm{C}$ NMR $(150.9 \mathrm{MHz}, \mathrm{DMSO}-\mathrm{d} 6) \delta 38.1$ $\left(\underline{\mathrm{CH}_{2}}\right), 38.3\left(\underline{\mathrm{CH}}_{2}\right), 39.2\left(\underline{\mathrm{CH}}_{2}\right), 55.5$ (quat. $\left.\underline{\mathrm{C}}\right), 81.0(\underline{\mathrm{CHOH}}), 111.4$ (tert. C), 112.9 (tert. $\underline{\text { C) }}, 120.4$ (tert. $\underline{\text { C), }} 124.1$ (quat. $\underline{\text { C), }} 124.2$ (tert. $\underline{\text { C) }}, 124.4$ (tert. $\underline{\mathrm{C}}), 126.2$ (tert. $\underline{\mathrm{C}}), 126.7(\underline{\mathrm{CH}}=\mathrm{C}), 127.5$ (tert. $\underline{\mathrm{C}}$ ), 128.3 (quat. C), $2 \times 128.5$ ( $2 \times$ tert. $\underline{\text { C) }}, 2 \times 129.9$ ( $2 \times$ tert. $\underline{\text { C }}), 135.8$ (quat. $\underline{\text { C) }}, 140.4$ (quat. $\underline{\mathrm{C}}$ ), 144.6 (quat. $\underline{\mathrm{C}}$ ), 145.1 (quat. $\underline{\mathrm{C}}$ ), 149.9 (quat. $\underline{\mathrm{C}}$ ), 154.7 (quat. C), 167.5 ( $\underline{\mathrm{COOH}})$. HRMS (ESI): $\mathrm{m} / \mathrm{z}$ calculated for $\mathrm{C}_{26} \mathrm{H}_{21} \mathrm{O}_{4}(\mathrm{M}-\mathrm{H})^{+}$, 397.1440; found 397.1436; [a]D $\mathrm{D}^{22}=-96.9^{\circ}(12.8 \mathrm{mg} / 1 \mathrm{~mL}, \mathrm{MeOH})$.

\section{Conclusion}

In summary, the in vitro metabolism study of the clinical candidate PH46A were studied by our group. Five metabolites were identified, including M1 (keto-PH46), M2 (PH46-OH or PH132), M3 (PH46-
diOH), M4 (keto-glucuronide-PH46) and M5 (glucuronide conjugatePH46) across species tested; while PH46 was confirmed in all samples at 0 and $240 \mathrm{~min}$ incubation time. Overall, all putative human metabolites were present in rat and dog. Metabolism in rat was most similar to human in terms of the metabolites observed. The order of clearance of PH46 was determined to be $\mathrm{rat}>\mathrm{dog}>$ monkey $>$ human. The species which exhibited the closest clearance values to the human was monkey. The rat produced the highest clearance of PH46 of all the species. Further studies will be carried out to investigate the stereochemistry of each metabolite to determine whether different stereoisomers of the metabolites were present following incubation.

We further developed an efficient biocatalytic method to generate one of the key metabolites, PH132, following an extensive screening of the selectAZyme panel of enzymes. Recombinant human liver 


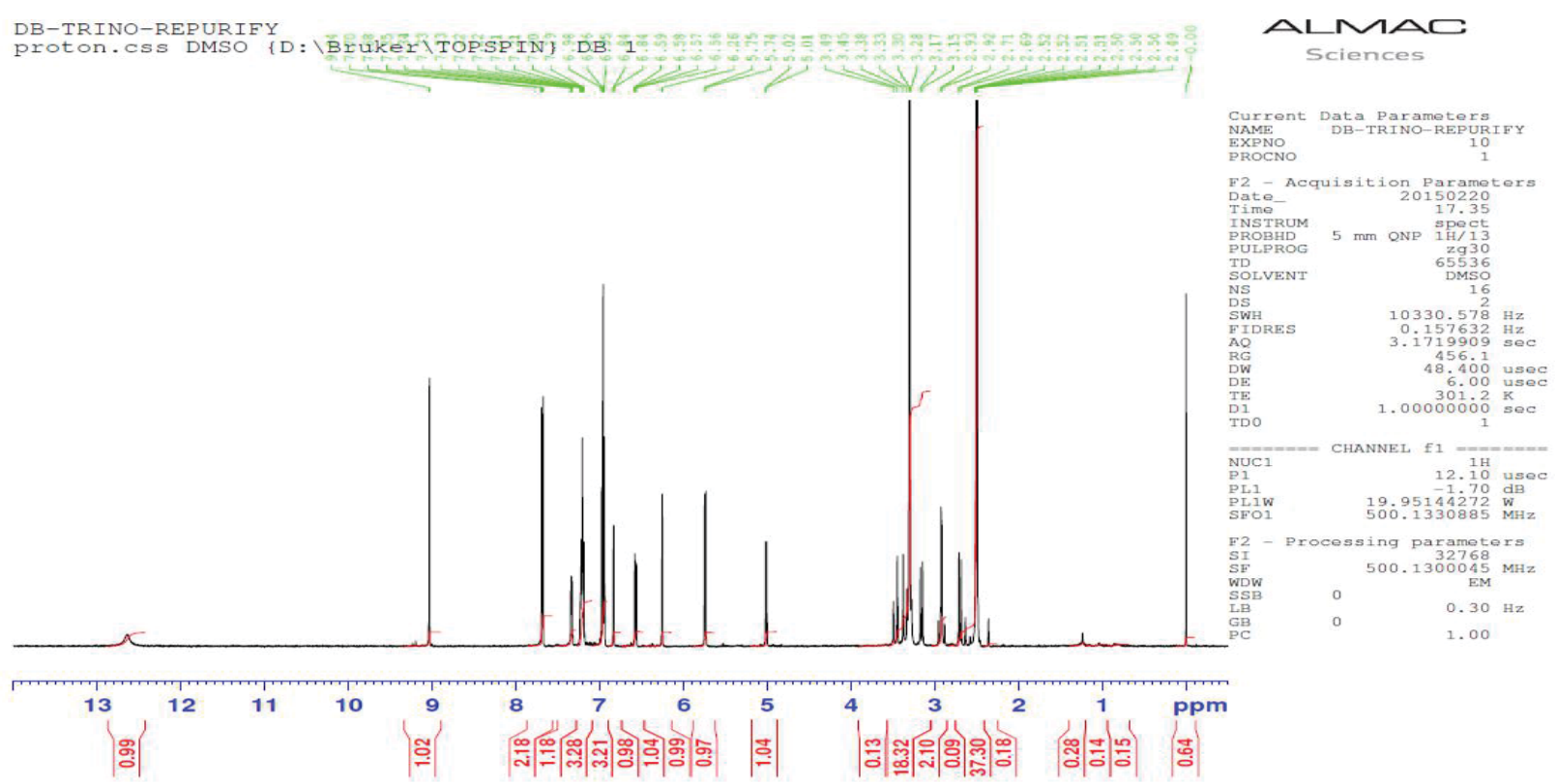

Figure 11: ${ }^{1} \mathrm{H}$ NMR spectrum of $\mathrm{PH} 132$.

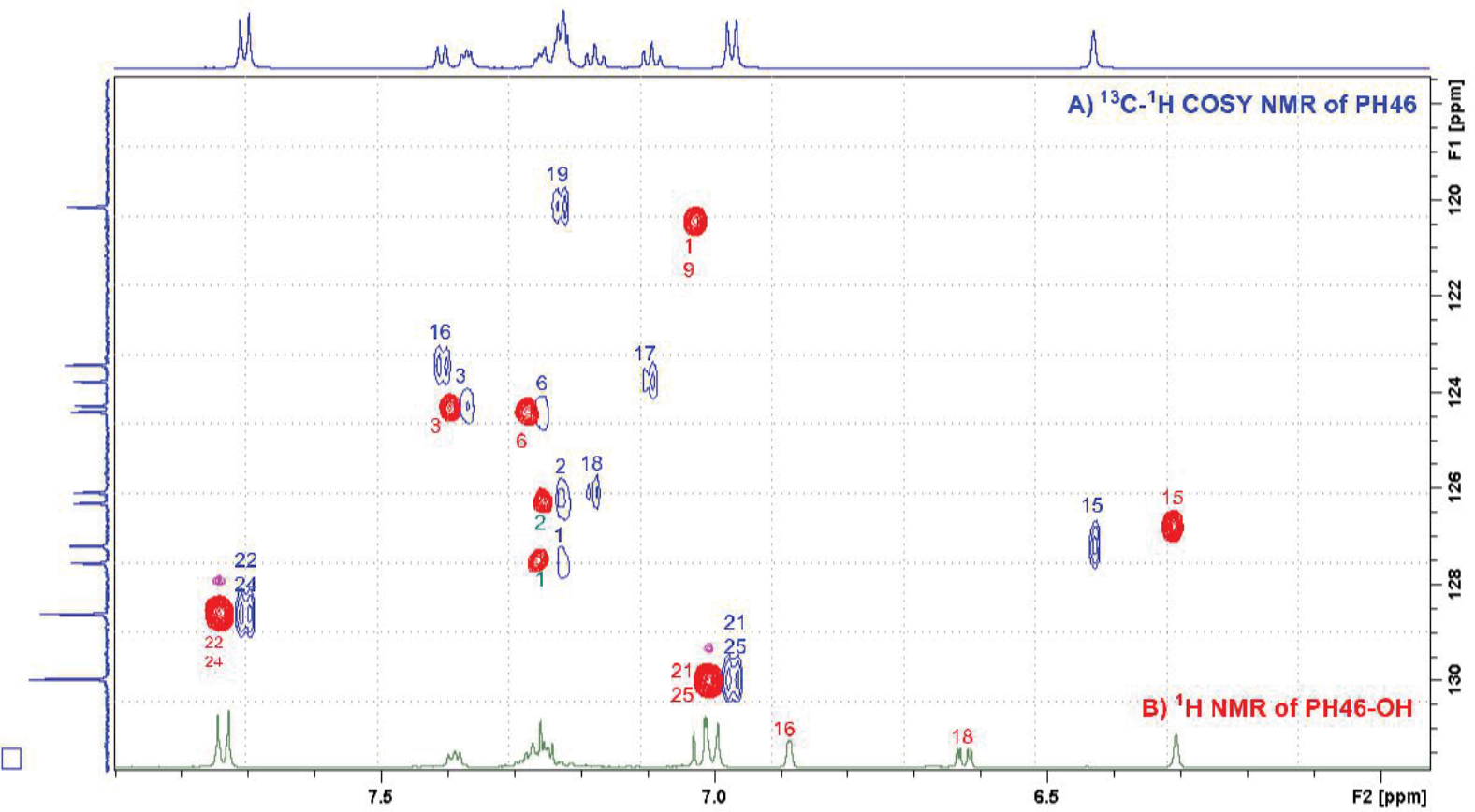

Figure 12: Spectra overlay of HSQC NMR spectrum of PH46 (blue) with HSQC (red) and ${ }^{1} \mathrm{H}$ (green) NMR spectra of PH132.

Cyps and RLM were identified as being capable of producing desired PH132, which was confirmed by a series of spiking experiments. RLM were selected for use for the subsequent scale-up reaction, and the full chemical structure characterisation of isolated and purified PH132 was confirmed by LC-MS/MS and a complete series of NMR experiments. It was revealed that the position of the $\mathrm{OH}$ moiety was at the $\mathrm{C} 17$ position locating on the aromatic ring of the indene system. The results obtained from the work are important for understanding the metabolism of PH46A in human and provide important information that may act as a reference for the next stage of pharmacokinetics, in vivo toxicology and clinical pharmacology investigations.

\section{Acknowledgment}

This work was supported by The Wellcome Trust under grant reference no. 067033/Z/02/A, Enterprise Ireland, Charles River (UK) and Almac Science (UK). 
Citation: Zhang T, Scalabrino G, Frankish N, Sheridan H (2018) Bioactive Indanes: Comparative in vitro Metabolism Study of PH46A, a New Potential Anti-inflammatory Agent and Biosynthesis of its Primary Metabolite PH132. J Drug Metab Toxicol 9: 239. doi:10.4172/2157-7609.1000239

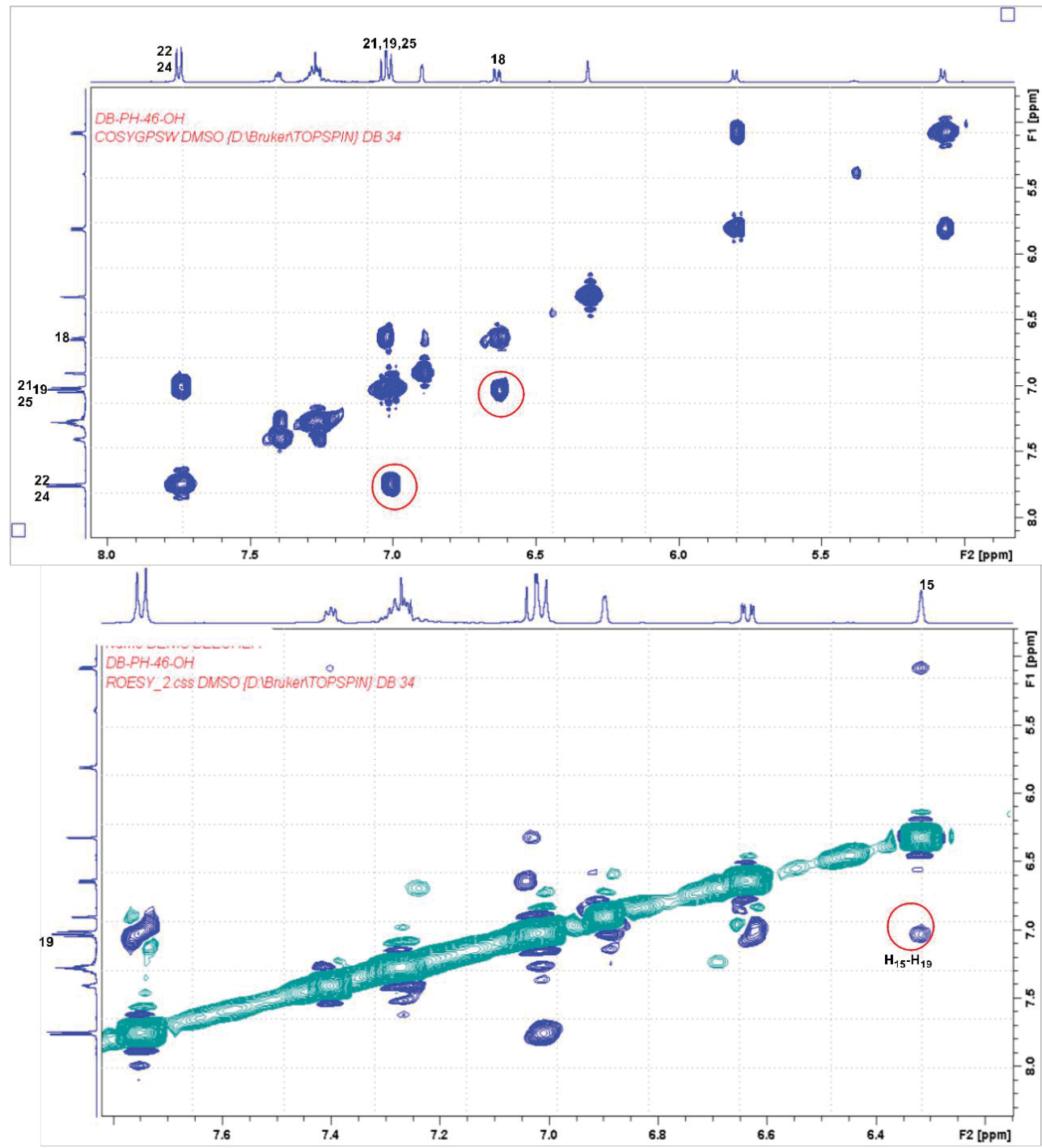

Figure 13a: ${ }^{1} \mathrm{H}-{ }^{1} \mathrm{H}$ COSY (upper) NMR spectra of $\mathrm{PH} 132$.

Figure 13b ROESY NMR spectra of PH132 (lower).

\section{Conflict of Interest}

The authors declare there is no conflict of interest.

\section{References}

1. Bai H, Chen X, Zhang L, Dou X (2012) The effect of sulindac, a non-steroidal anti-inflammatory drug, attenuates inflammation and fibrosis in a mouse model of chronic pancreatitis. BMC Gastroenterol 12: 115.

2. Shiff SJ, Qiao L, Tsai LL, Rigas B (1995) Sulindac sulfide, an aspirin-like compound, inhibits proliferation, causes cell cycle quiescence, and induces apoptosis in ht-29 colon adenocarcinoma cells. J Clin Invest 96: 491-503.

3. Scheper MA, Nikitakis NG, Chaisuparat R, Montaner S, Sauk JJ (2007) Sulindac induces apoptosis and inhibits tumor growth in vivo in head and neck squamous cell carcinoma. Neoplasia 9: 192-199.

4. Yao SW, Lopes VHC, Fernández F, Garciá-Mera X, Morales M, et al. (2003) Synthesis and qsar study of the anticancer activity of some novel indane carbocyclic nucleosides. Bioorg Med Chem 11: 4999-5006.

5. Prakasham AP, Saxena AK, Luqman S, Chanda D, Kaur T, et al. (2012) Synthesis and anticancer activity of 2-benzylidene indanones through inhibiting tubulin polymerization. Bioorg Med Chem 20: 3049-3057.
6. Luan F, Cordeiro MNDS, Alonso N, García-Mera X, Caamaño O, et al (2013) Tops-mode model of multiplexing neuroprotective effects of drugs and experimental-theoretic study of new 1,3-rasagiline derivatives potentially useful in neurodegenerative diseases. Bioorg Med Chem 21: 1870-1879.

7. Melillo B, Liang S, Park J, Schön A, Courter JR, et al. (2016) Small-molecule cd4-mimics: Structure-based optimization of hiv-1 entry inhibition. ACS Med Chem Lett 7: 330-334.

8. Zhang T, McCabe T, Marzec B, Frankish N, Sheridan H (2012) N-cyclo-pentyl$\mathrm{N}$-(3-oxo-2,3-dihydro-1H-inden-1-yl) acetamide. Acta Cryst E: 1600-5368.

9. Zhang T, Paluch K, Scalabrino G, Frankish N, Healy A-M, et al. (2015) Molecular structure studies of $(1 \mathrm{~S}, 2 \mathrm{~S})-2-$ benzyl-2,3-dihydro-2-(1H-inden-2-yl)1H-inden-1-ol. J Mol Struct 1083: 286-299.

10. Frampton CS, Zhang T, Scalabrino GA, Frankish N, Sheridan H (2012) (1S)-1-phenylethanaminium $4-\left\{\left[(1 \mathrm{~S}, 2 \mathrm{~S})\right.\right.$-1-hydroxy-2,3-dihydro-1 $\mathrm{H}, 1^{\prime} \mathrm{H}-[2,2$ '-biinden]-2-yl]methyl\}benzoate. Acta Cryst C 68: o323-0326.

11. Sheridan H, Lemon S, Frankish N, McArdle P, Higgins T, et al. (1990) Synthesis and antispasmodic activity of nature identical substituted indanes and analogues. Eur J Med Chem 25: 603-608. 
Citation: Zhang T, Scalabrino G, Frankish N, Sheridan H (2018) Bioactive Indanes: Comparative in vitro Metabolism Study of PH46A, a New Potential Anti-inflammatory Agent and Biosynthesis of its Primary Metabolite PH132. J Drug Metab Toxicol 9: 239. doi:10.4172/2157-7609.1000239

Page 14 of 14

12. Sheridan H, Frankish N, Farrell R (1999) Synthesis and antispasmodic activity of analogues of natural pterosins. Eur J Med Chem 34: 953-966.

13. Sheridan H, Frankish N, Farrell R (1999) Smooth muscle relaxant activity of pterosin z and related compounds. Planta Medica 65: 271-272.

14. Frankish N, Farrell R, Sheridan H (2004) Investigation into the mast cell stabilizing activity of nature-identical and synthetic indanones. J Pharm Sci Exp Pharmacol 56: 1423-1427.

15. Sheridan H, Walsh JJ, Jordan M, Cogan C, Frankish N (2009) A series of 1, 2-coupled indane dimers with mast cell stabilisation and smooth muscle relaxation properties. Eur J Med Chem 44: 5018-5022.

16. Sheridan H, Walsh JJ, Cogan C, Jordan M, McCabe T, et al. (2009) Diastereoisomers of 2-benzyl-2, 3-dihydro-2-(1H-inden-2-yl)-1H-inden-1-ol: Potential anti-inflammatory agents. Bioorg Med Chem Lett 19: 5927-5930.

17. Frankish N, Sheridan H (2012) 6-(methylamino)hexane-1,2,3,4,5-pentanol 4-(((1S,2S)-1-hydroxy-2,3-dihydro-1 $\mathrm{H}, 1^{\prime} \mathrm{H}-[2,2-$ biinden]-2-yl)methyl)benzoate (PH46A): A novel small molecule with efficacy in murine models of colitis. $J$ Med Chem 55: 5497-5505.

18. Cumming GR, Zhang T, Scalabrino G, Frankish N, Sheridan H (2017) Investigation of the stereoselective synthesis of the indane dimer PH46A, a new potential anti-inflammatory agent. Org Process Res Dev 21: 1972-1979.

19. www.isrctn.com/ISRCTN90725219
20. Zhang D, Luo G, Ding X, Lu C (2012) Preclinical experimental models of drug metabolism and disposition in drug discovery and development. Acta Pharmaceutica Sinica B 2: 549-561.

21. Bernhardt R (2006) Cytochromes P450 as versatile biocatalysts. J Biotechnol Biomed 124: 128-145.

22. Chefson A, Auclair K (2006) Progress towards the easier use of p450 enzymes. Molecular BioSystems 2: 462-469.

23. Teyssier C, Guenot L, Suschetet M, Siess M-H (1999) Metabolism of diallyl disulfide by human liver microsomal cytochromes $\mathrm{P} 450$ and flavin-containing monooxygenases. Drug Metab Dispos 27: 835-841.

24. Strober W (2001) Trypan blue exclusion test of cell viability. Current Protocols in Immunology Appendix 3: Appendix 3B.

25. Naritomi Y, Terashita S, Kagayama A, Sugiyama Y (2003) Utility of hepatocytes in predicting drug metabolism: Comparison of hepatic intrinsic clearance in rats and humans in vivo and in vitro. Drug Metabolism and Disposition 31: 580-588.

26. Sohlenius-Sternbeck AK (2006) Determination of the hepatocellularity number for human, dog, rabbit, rat and mouse livers from protein concentration measurements. Toxicology in vitro 20: 1582-1586.

27. Davies B, Morris T (1993) Physiological parameters in laboratory animals and humans. J Pharm Pharm Sci 10: 1093-1095.

28. UK CRE (2013) Physiological parameters of monkey: Number of hepatocytes per gram of liver weight; gram of liver weight per $\mathrm{kg}$ of body weight. Unpublished data. 